\title{
Characteristic nature of vertical motions observed in Arctic mixed-phase stratocumulus
}

\author{
J. Sedlar ${ }^{1,2}$ and M. D. Shupe ${ }^{3}$ \\ ${ }^{1}$ Department of Meteorology, Stockholm University, Stockholm, Sweden \\ ${ }^{2}$ Bert Bolin Centre for Climate Research, Stockholm University, Stockholm, Sweden \\ ${ }^{3}$ Cooperative Institute for Research in Environmental Science, University of Colorado and NOAA Earth System Research \\ Laboratory, Boulder, CO, USA
}

Correspondence to: J. Sedlar (josephs@misu.su.se)

Received: 30 October 2013 - Published in Atmos. Chem. Phys. Discuss.: 28 November 2013

Revised: 24 February 2014 - Accepted: 25 February 2014 - Published: 7 April 2014

\begin{abstract}
Over the Arctic Ocean, little is known on cloud-generated buoyant overturning vertical motions within mixed-phase stratocumulus clouds. Characteristics of such motions are important for understanding the diabatic processes associated with the vertical motions, the lifetime of the cloud layer and its micro- and macrophysical characteristics.

In this study, we exploit a suite of surface-based remote sensors over the high-Arctic sea ice during a weeklong period of persistent stratocumulus in August 2008 to derive the incloud vertical motion characteristics. In-cloud vertical velocity skewness and variance profiles are found to be strikingly different from observations within lower-latitude stratocumulus, suggesting these Arctic mixed-phase clouds interact differently with the atmospheric thermodynamics (cloud tops extending above a stable temperature inversion base) and with a different coupling state between surface and cloud. We find evidence of cloud-generated vertical mixing below cloud base, regardless of surface-cloud coupling state, although a decoupled surface-cloud state occurred most frequently. Detailed case studies are examined, focusing on three levels within the cloud layer, where wavelet and power spectral analyses are applied to characterize the dominant temporal and horizontal scales associated with cloud-generated vertical motions. In general, we find a positively correlated vertical motion signal amongst vertical levels within the cloud and across the full cloud layer depth. The coherency is dependent upon other non-cloud controlled factors, such as larger, mesoscale weather passages and radiative shielding of lowlevel stratocumulus by one or more cloud layers above. De-
\end{abstract}

spite the coherency in vertical velocity across the cloud, the velocity variances were always weaker near cloud top, relative to cloud middle and base. Taken in combination with the skewness, variance and thermodynamic profile characteristics, we observe vertical motions near cloud top that behave differently than those from lower within the cloud layer. Spectral analysis indicates peak cloud-generated $w$ variance timescales slowed only modestly during decoupled cases relative to coupled; horizontal wavelengths only slightly increased when transitioning from coupling to decoupling. The similarities in scales suggests that perhaps the dominant forcing for all cases is generated from the cloud layer, and it is not the surface forcing that characterizes the time- and space scales of in-cloud vertical velocity variance. This points toward the resilient nature of Arctic mixed-phase clouds to persist when characterized by thermodynamic regimes unique to the Arctic.

\section{Introduction}

Clouds are the manifestation of physical processes occurring over a wide range of spatial and temporal scales. Local thermodynamics, large-scale meteorological forcing, boundary layer and cloud-scale circulations, and aerosol size and number concentrations influence the presence, type, macrophysical and microphysical characteristics of clouds. Stratocumulus occur frequently over subtropical marine regions where persistent subsidence, relatively cool surface water temperatures and aerosol populations largely determined by 
the ocean surface limit their vertical extent and control their microphysical nature (e.g., Paluch and Lenschow, 1991). These clouds exhibit a strong global climate signal, wherein their shortwave climate cooling effect outweighs their warming longwave greenhouse effect (e.g., Klein and Hartmann, 1993).

Like their subtropical counterparts, Arctic stratocumulus are also frequently present during all seasons, peaking in frequency during late summer and autumn (Curry et al., 1996; Shupe et al., 2011). In contrast to the subtropics, Arctic stratocumulus are often mixed phase (AMPS - Arctic mixedphase stratocumulus), where liquid droplets and ice crystals coincide within the same volume of air (e.g., Herman and Goody, 1976; Curry, 1986). Additionally, conditions unique to the Arctic - including low solar angles, highly reflective surfaces and a relatively cool and dry atmosphere - generally reverse the net surface radiative effect of these clouds, frequently resulting in a warming at the surface (Walsh and Chapman, 1998; Intrieri et al., 2002a; Shupe and Intrieri, 2004; Sedlar et al., 2011). Using observations from late autumn, Sedlar et al. (2011) describe the important role of surface cloud radiative forcing in regulating the surface temperature and influencing the transition from Arctic surface melt season to autumn freeze. To understand the Arctic surface energy budget and lower-atmospheric thermodynamic and turbulence structure, an understanding of the quasi-persistent (Curry et al., 1996) low-level Arctic clouds is critical. This understanding becomes potentially more important as the Arctic climate warms, leading to less sea ice and a darker, more absorptive ocean surface.

AMPS, like their lower-latitude counterparts, are maintained, in part, via turbulent kinetic energy (TKE) production through longwave cooling at cloud top (Nicholls and LeMone, 1980; Curry, 1986; Moeng, 1986; Nicholls and Leighton, 1986; Paluch and Lenschow, 1991; Klein and Hartmann, 1993; Paluch et al., 1997; Lothon et al., 2005). Vertical motions associated with top-down buoyancy circulations mix the atmosphere across the cloud depth and below cloud base, leading to production and dissipation of cloud condensate (Paluch and Lenschow, 1991). More often than not, these clouds consist of a layer of liquid droplets, with ice crystals formed within this layer falling from the liquid base (e.g., Shupe, 2011). A direct connection between vertical motions within the cloud and the production/dissipation of cloud liquid and ice has been observed in AMPS (Shupe et al., 2008a); ice and liquid generally increase as parcels cool adiabatically in updrafts, while ice production diminishes during compensating downdrafts as liquid droplets evaporate. This process suggests that the presence of ice in these clouds depends first on the availability of liquid (e.g., de Boer et al., 2011), which in turn depends on the vertical velocity within the cloud layer, which in turn depends on the efficient cooling to space through the presence of liquid, and so on and so forth (e.g., Morrison et al., 2012). An understanding of cloud vertical motions is therefore crucial for understanding cloud persistence, microphysics and macrophysical structure.

Surface-based remote sensing observations appropriate for estimating in-cloud vertical motions over the Arctic are sparse. Thus, characteristics of vertical motions in AMPS are generally not well understood. Estimates of the magnitude, direction (up- and downdrafts) and dominant timespace scales of Arctic cloud vertical motions are often limited to experimental campaigns around the pan-Arctic continents (Pinto, 1998; Shupe et al., 2008a; McFarqhuar et al., 2011), or they are estimated numerically using large eddy simulations forced by "typical" Arctic conditions (Harrington et al., 1999; Solomon et al., 2011). Such "typical” conditions can span a large range due to the wide thermodynamic, surface and meteorological conditions influencing the Arctic over the annual cycle.

Relatively recent studies on AMPS in-cloud vertical velocity $(w)$ have identified characteristic cloud overturning timescales on the order of 10 min (Pinto, 1998; Shupe et al., 2008a, 2012). These characteristic motions have been linked to the persistent nature of AMPS through the nearly continuous generation of cloud condensate, regulated in magnitude by ice crystal formation and precipitation processes (Shupe et al., 2008a). In this study, we exploit surface-based remote sensing observations from the high-latitude Arctic Summer Cloud Ocean Study (ASCOS; Sedlar et al., 2011; Tjernström et al., 2014) to examine in-cloud $w$ characteristics and identify processes associated with these motions. Statistical analyses of in-cloud $w$ are analyzed across the full cloud depth, and at relative levels within cloud, to understand some fundamental questions regarding vertical motion within AMPS:

1. How does lower-tropospheric thermodynamic structure affect where in-cloud buoyancy production occurs relative to cloud top?

2. What role does coupling or decoupling between the surface and cloud layer have on in-cloud $w$ ?

3. Are buoyancy-produced vertical motions coherent across the cloud layer, and how are they impacted by coupling state?

In subsequent sections, we refer back to these fundamental questions to aid in interpreting the results based on observed thermodynamic structure, coupling state and coherency of vertical motions across the cloud.

This study is organized as follows: Sect. 2 contains a brief introduction to the ASCOS instrumentation and methods of analysis, Sect. 3 examines the characteristic profiles of velocity and thermodynamics, Sect. 4 examines the temporal frequency of $w$ variance and covariance at 3 elevations within the cloud, Sect. 5 examines the relationships between cloudgenerated $w$ variability and the coupling nature between the surface and the cloud, and finally a discussion of results and the following conclusions are presented in Sects. 6 and 7. 


\section{Analysis methods}

\subsection{ASCOS}

In support of the International Polar Year 2007-2010, ASCOS operated within the central (approximately $87.5^{\circ} \mathrm{N}$ ) Arctic Ocean during the 2008 seasonal transition from sea ice melt to the onset of ice freeze (12 August-1 September 2008). This campaign was conceived to address the knowledge gap of, among many others, surface-atmosphere-cloud processes and interactions that may be critical in the development and persistence of Arctic stratocumulus. Contributing to the community's understanding of low-level $(<2.5 \mathrm{~km}$ above the surface) cloud processes over the Arctic, a number of ASCOS process-oriented studies relating to such interactions have recently been conducted (e.g., Sedlar et al., 2011; Mauritsen et al., 2011; Birch et al., 2012; Shupe et al., 2012; 2013; Tjernström et al., 2012; Kuzpiewski et al., 2013; Sotiropoulou et al., 2014). The entire timeline of ASCOS is meticulously detailed in Tjernström et al. (2014), including extensive descriptions of the instrumentation and measurements, and so only the necessary details are provided below.

\subsection{Measurements and velocity estimation method}

This study utilizes a number of surface-based remote sensing instruments to analyze cloud properties and atmospheric thermodynamic structure. The heart of the cloud analysis relies on observations from the vertically pointing Doppler millimeter cloud radar (MMCR; see Moran et al., 1998). The full Doppler radar spectrum can be analyzed to estimate $w$ velocities at each vertical range gate ( $45 \mathrm{~m}$ resolution). Generally, the fall speed of ice crystals increases with increasing size (Pruppacher and Klett, 1996), while cloud droplets are much smaller and have negligible fall speeds - thus moving with the vertical air motions (e.g., Shupe et al., 2008a). Using these principles, the background noise in the Doppler spectra is removed (e.g., Hildebrand and Sekhon, 1974), and vertical air motions coming from the cloud droplet signal are retained and provide estimates of $w$. This method only works if cloud liquid is present (droplets); thus a ceilometer is used to identify the location of a liquid cloud base. Additionally, 23 and $30 \mathrm{GHz}$ microwave radiometer (MWR) measurements are used to derive the column-integrated liquid water path (LWP) with an uncertainty of about $25 \mathrm{~g} \mathrm{~m}^{-2}$ (Westwater et al., 2001). If both instruments suggest the presence of liquid, $w$ profiles are estimated from the MMCR Doppler spectra at each range gate above liquid cloud base and below cloud top using the slowest falling, or fastest lifting, spectral edge (see Shupe et al., 2008b). These instruments have varying temporal resolution, varying from $4 \mathrm{~s}$ (MMCR) to $30 \mathrm{~s}$ (MWR); to facilitate comparisons, the remote sensors are linearly interpolated to the relatively fast, $4 \mathrm{~s}$ MMCR temporal frequency.

If the intent is to examine cloud $w$, various corrections must be applied (Shupe et al., 2008b). These correct for spec- tral broadening effects related to turbulence, shear and other influences. However, such corrections, which are uncertain, can be foregone entirely here as we focus on statistical parameters related to the temporal variability of velocities and not the actual velocity itself. Power spectra and wavelet analyses of temporal variability, variance and skewness of vertically resolved $w$ are such statistical parameters that are examined in this paper. They provide information on the important timescales interacting within various elevations of the cloud layer, impacts of upper cloud layers shielding lower layers, and the role of static stability within and below the cloud layer on $w$ variability.

The technique to derive vertical motions is known to introduce a positive velocity bias (Shupe et al., 2008b). To account for this bias, we have removed the 30 min running average vertical velocity (corrected $w$ ) from each range gate where an in-cloud $w$ was observed and performed comparisons of the statistical parameters between these and the uncorrected $w$ profiles. As expected, the statistics changed negligibly between the corrected and uncorrected $w$ datasets because the parameters studied are dependent on the variances of time-evolving motions; when transformed to Fourier wave-space, the absolute values have no contribution to the timescales of dominant motions. Subsequently, the results will be shown for the uncorrected $w$ profiles, except for an example case that will be first discussed in Sect. 3.1. We further motivate using the uncorrected $w$ for statistical analysis because removing a $30 \mathrm{~min}$ running averaged $w$ biases any temporal analysis on timescales longer than $30 \mathrm{~min}$, which we use to identify the influence of longer time- (and presumably space-) scales associated with larger, mesoscale motions (e.g., Tjernström and Mauritsen, 2009).

Radiosoundings, released at $6 \mathrm{~h}$ intervals, provide profiles of thermodynamic properties and wind speed profiles. To enhance the temporal coverage, scanning $60 \mathrm{GHz}$ microwave radiometer retrievals of $5 \mathrm{~min}$ averaged vertical temperature profiles up to $1.2 \mathrm{~km}$ are also analyzed. The retrieval uses brightness temperature measurements to improve upon an a priori data set based on interpolated radiosonde data; see Westwater et al. (1999) for a detailed description of the temperature profile retrieval method. The information content from the scanning radiometer slowly diminishes with height, but generally has a root-mean-square error (RMSE) less than $1{ }^{\circ} \mathrm{C}$ (Westwater et al., 1999) relative to independent, linearly interpolated radiosondes below $700 \mathrm{~m}$ a.g.l at ASCOS (P. O. G. Persson, personal communication, 2013). The bias in scanning radiometer temperatures relative to radiosoundings was generally smaller than $-0.2^{\circ} \mathrm{C}$ (P. O. G. Persson, personal communication, 2013).

To further characterize the impact of stability between the surface and cloud layer, we use MMCR-derived estimates of turbulent dissipation rate $(\varepsilon)$. Profiles of $\varepsilon$ are estimated using temporal variance of the first Doppler moment, namely the mean Doppler velocity; details of the estimation method are given in Shupe et al. (2012). The $\varepsilon$ retrieval can be applied 


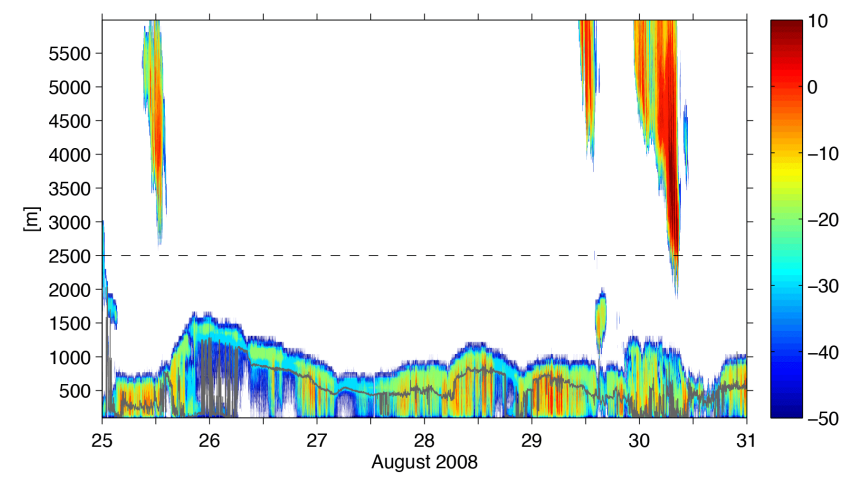

Fig. 1. Cloud reflectivity (contours, $[\mathrm{dBZ}]$ ) observed from the vertically pointing MMCR radar at ASCOS over the week 25-30 August 2008. The MMCR is sensitive to hydrometeor size, and often reflectivities larger than $-17 \mathrm{dBZ}$ are representative of larger drizzle or ice hydrometeors. The lowest cloud base observed from the ceilometer (gray) overlays the cloud radar reflectivity; the ceilometer is sensitive to the liquid cloud base height. Thus reflectivities below cloud base indicate hydrometeors falling from the liquid cloud. Only low-level clouds below $2500 \mathrm{~m}$ a.g.1 (dashed horizontal line) are examined in this study.

to all volumes containing hydrometeors (cloud and precipitation) as long as they surpass a minimum signal-to-noise ratio. From the $\varepsilon$ profiles, Shupe et al. (2013) estimate the base of the cloud-driven mixed layer for precipitating AMPS, under the assumption that following mixed-layer theory, the turbulence characteristics within a mixed layer are isotropic and constant. The mixed-layer base is identified where $\varepsilon$ falls below an arbitrary threshold of $5 \times 10^{-5} \mathrm{~m}^{2} \mathrm{~s}^{-3}$. When the base of the cloud mixed layer is above (reaching) the surface, the cloud-generated turbulent motions are considered decoupled (coupled) from (with) turbulence generated by the surface. Since the radar's first vertical range gate is $100 \mathrm{~m}$ a.g.l, we assume a fully coupled surface-cloud state when the mixedlayer base is below $150 \mathrm{~m}$ a.g.l (Shupe et al., 2013).

\subsection{Cloud situation}

The period of study is a generally high-pressure-dominated week, where low-level AMPS are present the entire time 25-30 August 2008. This week was analyzed extensively by Sedlar et al. (2011) and shown to be critical in delaying the onset of seasonal surface freeze due to an enhanced warming from cloud longwave radiative surface forcing. Multiple cloud layers were observed on 25, 29 and 30 August; cloud reflectivity and liquid cloud base for the lowest $6 \mathrm{~km}$ are shown in Fig. 1. For subsequent statistical analysis of $w$, any situation with more than one cloud layer below $2.5 \mathrm{~km}$ is neglected from the analysis. The reason for exclusion is that $w$ estimates can only be made in volumes containing liquid droplets, and we cannot be sure of the vertical distribution of MWR-derived LWP in multiple low-level clouds - the value is column-integrated. This limitation results in $121 \mathrm{~h}$ of low-
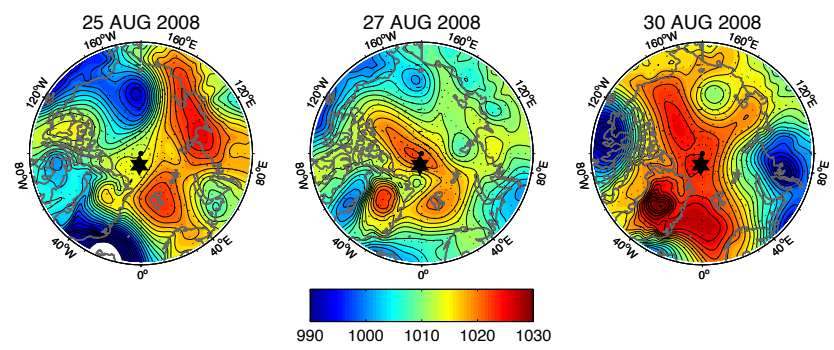

Fig. 2. ERA-Interim mean sea-level pressure (contours $[\mathrm{hPa}]$ ) at 12:00 UTC for three snapshots: 25 August (left), 27 August (middle) and 30 August (right). The general location of ASCOS during this week is shown by the filled black hexagram.

level cloud observations - approximately $90 \%$ data coverage for this period. Despite a large-scale, high-pressure influence (Fig. 2), a number of weak frontal passages advected past the ASCOS location during this week (Tjernström et al., 2012). Changes in the low-level cloud structure correspond to distinct shifts associated with advective changes; however the low AMPS cloud is resilient and persists the entire week. Despite the short duration of observations, the quality, temporal resolution and physical location of this study provide a wealth of detail regarding in-cloud vertical motion characteristics in an under-studied region. Physical characteristics of clouds during this week bear a strong resemblance to longterm observations conducted at other pan-Arctic observatories and for different times (Intrieri et al., 2002b; Shupe et al., 2006, 2008a; de Boer et al., 2009; Shupe, 2011; Sedlar et al., 2012); thus in-depth analysis of this week of data can provide insight into the processes at work within AMPS. More importantly, this study deals with AMPS over a sea-ice environment; past campaigns either fail to capture an isolated, high-Arctic sea-ice environment or they lack the necessary instrumentation to obtain the $w$ characteristics examined in this study. The reader must bear in mind that the following results and analysis are essentially snapshots during a brief time period dominated by low AMPS. Nevertheless, one could incorporate the results given here with large eddy simulation analysis where large-scale forcing, and cloud macroand microphysical conditions are varied to test the sensitivity of cloud responses (e.g., Harrington et al., 1999; Solomon et al., 2011).

\section{Statistical results}

\subsection{Methods of $w$ characteristics and example case}

Vertically resolved profiles of corrected $w$ for 27 August 2008 are presented in Fig. 3 for a primarily single-layer AMPS with varying thickness between 475 and $850 \mathrm{~m}$. Velocities shown in Fig. 3a are typical of the profiles during this weeklong AMPS period, with intermittent upward and downward motions across the cloud layer. In Fig. 3b, 20 min 
running window $\sigma_{w}^{2}$ profiles are generally smallest and relatively homogeneous in approximately the upper third (on average, the upper $75-150 \mathrm{~m}$ ) of the cloud layer, but below this level, $\sigma_{w}^{2}$ increases towards its maximum observed value and generally remains large and homogeneous down to cloud base. Running windows of $20 \mathrm{~min}$ were chosen to cover the peak spectral timescales in $w$ on the order of 8 min reported by Shupe et al. (2012). Skewness provides a statistical measure of the wings of a data distribution. Vertical velocity skewness $\left(S_{w}\right)$ is calculated at each range gate within the cloud layer following

$$
S_{w}=\frac{\frac{1}{N} \sum_{i=1}^{N}\left(w_{i}-\bar{w}\right)^{3}}{\left(\frac{1}{N} \sum_{i=1}^{N}\left(w_{i}-\bar{w}\right)^{2}\right)^{3 / 2}},
$$

where $N$ is the number of observations within a moving 20 min window (mean $w$ calculated for each 20 min window). Both $S_{w}$ and $\sigma_{w}^{2}$ estimates are retained only when more than $50 \%$ of $w$ estimates within the 20 min window are available at each MMCR range gate. $S_{w}$ within this example cloud scene (Fig. 3c) reveals a distinct interface generally in the upper half of the cloud layer where $S_{w}$ changes sign. The upper portion of the cloud (top $\sim 100 \mathrm{~m}$ ) clearly indicates positive $S_{w}$ (associated with stronger, narrower updrafts), while negative $S_{w}$ below the interface is suggestive of stronger, narrower downdrafts. The depth of the negative $S_{w}$ layer within the cloud increases with increasing cloud depth, while being most shallow, and apparently weaker, when the cloud layer is thinner. Typically, lower-latitude stratocumulus are sustained by cloud-top radiative cooling that generates TKE buoyant mixing (e.g., Paluch and Lenschow, 1991). Profiles of $S_{w}$ in these lower-latitude clouds are generally negative as a result of the stronger and narrower downdrafts driven by cloud top radiative cooling (Hogan et al., 2009). The vertical $S_{w}$ distributions over the high-latitude sea ice on 27 August 2008 (Fig. 3c), and for additional periods discussed below, are therefore strikingly different (e.g., Shupe et al., 2013).

The velocity-based signatures in Fig. $3 \mathrm{~b}$ and $\mathrm{c}$ highlight different processes affecting the vertical motion at different elevations within the cloud layer. To characterize velocity statistics over the full week, normalized height profiles $\left(z_{\mathrm{n}}\right)$ are calculated relative to the cloud boundaries following

$z_{\mathrm{n}}=\frac{z-z_{1}}{z_{2}-z_{1}}$

where $z_{2}$ and $z_{1}$ are the combined ceilometer-radar-derived cloud-top and base heights, respectively. We use normalized height profiles for subsequent analysis of $w$ characteristics within the full cloud layer (base to top) and for three in-cloud elevations (base, $z_{\mathrm{n}}=0.2$; mid, $z_{\mathrm{n}}=0.5$; top, $z_{\mathrm{n}}=0.8$ ) broadly matching where the statistical characteristics of Fig. 3 indicate differences dependent upon in-cloud elevation.

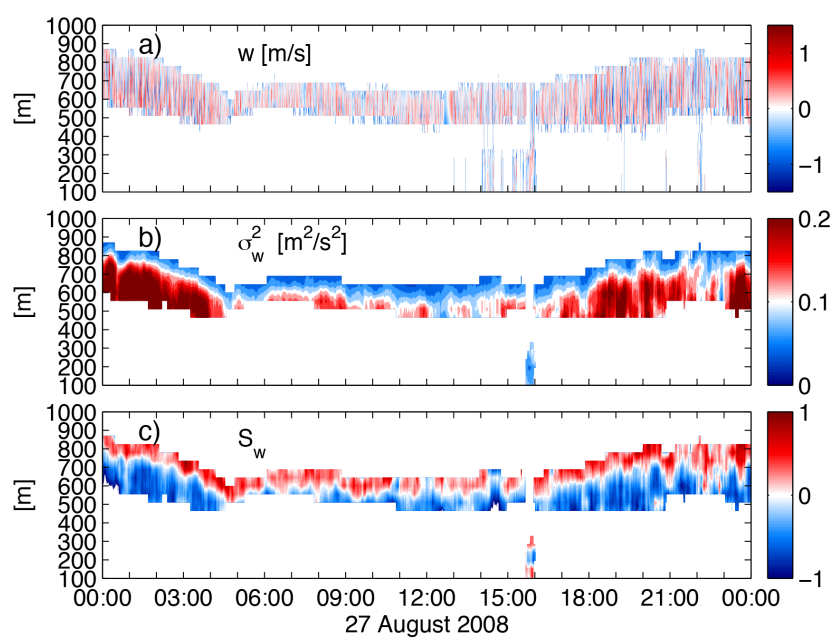

Fig. 3. Example of vertically resolved (a) $w$ estimates $\left[\mathrm{m} \mathrm{s}^{-1}\right]$, warm (cold) contours indicate ascending (descending) motions; (b) $w$ variance $\left(\sigma_{w}^{2}\right)\left[\mathrm{m}^{2} \mathrm{~s}^{-2}\right]$; and (c) $w$ skewness $\left(S_{w}\right)$ from $27 \mathrm{Au}-$ gust 2008. Both $\sigma_{w}^{2}$ and $S_{w}$ are calculated for a 20 min moving window at each radar range gate.

\section{2 $S_{w}$ in low-level AMPS}

$S_{w}$ is estimated for all times during 25-30 August 2008 when a single cloud layer was observed below $2.5 \mathrm{~km}$; times when additional cloud layers above $2.5 \mathrm{~km}$ are located over the single lower layer are included in the analysis if the radar signatures indicate they are not liquid-bearing clouds (i.e., midto-high-level ice clouds) Low-level clouds are normalized in height following Eq. (2).

Despite substantial spread in the interquartile ranges, median $S_{w}$ generally shows a profile that transitions from negative skewness to positive skewness with an interface near $z_{\mathrm{n}}=0.6-0.7$ (Fig. 4, black). Median values tend to increase with elevation away from this interface, more negative below and more positive above. The transition in median $S_{w}$ sign with height is significant at the $99 \%$ confidence level following the two-sided Wilcoxon rank-sum test and therefore a robust feature of these low-level AMPS (Shupe et al., 2013). The nature of the $S_{w}$ profile in AMPS during ASCOS reflects an important process occurring within these clouds: the general notion of top-down buoyancy generation being largest near cloud top, as understood from lower-latitude cloud studies (e.g., Paluch and Lenschow, 1991; Hogan et al., 2009), is not reflected here. Instead the generation of stronger, narrower buoyancy downdrafts often occurs from the cloud interior, below approximately $z_{\mathrm{n}}=0.6$.

Vertically resolved $S_{w}$ statistics for the subsampled period 26-28 August are also included in Fig. 4; this period is included as there are very few instances of multilayered clouds above the main AMPS layer, which had liquid cloud boundaries observed primarily between 600 and $1500 \mathrm{~m}$ a.g.l. While the normalized in-cloud profile shape is 


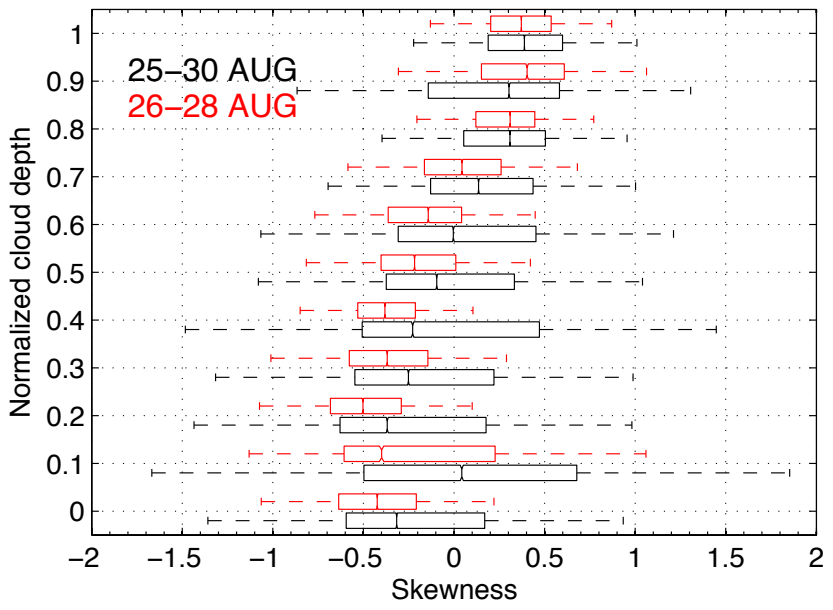

Fig. 4. In-cloud vertical velocity skewness $\left(S_{w}\right)$ distribution as a function of normalized in-cloud height ( 0 is cloud base and 1 is cloud top; see Eq. 1). Rectangles represent the 25th-75th percentile range, vertical lines within the rectangles represent median values and the dashed lines indicate the 5th-95th percentiles. Data for the week 25-30 August are in black, and for a shorter period, 26-28 August, in red.

similar to the near-weeklong period of 25-30 August, $S_{w}$ median magnitudes are enhanced. This is particularly true for the negative skewness found below $z_{\mathrm{n}}=0.6$. Without cloud shielding from above this layer, the cloud is presumably able to cool more effectively to space via longwave radiation, leading to a cloud layer more actively generating negative buoyancy.

\subsection{Static stability}

The question that emerges is, why are median $S_{w}$ estimates near cloud top positive, while becoming negative only below a certain depth within the cloud layer? Here we examine static stability for both the in-cloud and sub-cloud layers, eluding to the first fundamental question proposed in Sect. 1 regarding how in-cloud thermodynamic structure relates to cloud buoyancy production. Vertical gradients in potential temperature $(\theta)$ from 10 min scanning radiometer profiles and $6 \mathrm{~h}$ radiosoundings are calculated to approximately identify layers of static stability $(\delta \theta>0)$, neutral static stability $(\delta \theta \approx 0)$ and static instability $(\delta \theta<0)$. Figure 5 shows the distribution of $\delta \theta$ on a normalized height grid (Eq. 2) derived as the difference in $\theta$ between consecutive vertical grid resolution from the scanning radiometer $(10 \mathrm{~m})$ and radiosoundings ( $5 \mathrm{~m}$ below $1000 \mathrm{~m}$ a.g. $1 ; 10 \mathrm{~m}$ between 1000 and $1500 \mathrm{~m}$ a.g.l); the distributions are centered around a normalized height grid of $z_{\mathrm{n}}=0.1$. It is important to note that $\delta \theta$ from native, coincident instrument vertical bins is small relative to the instrument bias discussed above in Sect. 2.2.

In a statistical sense, in-cloud $\delta \theta$ profiles indicate nearneutral to slightly stable static stability from cloud base upwards in elevation to approximately cloud mid-level (Fig. 5a). Neutral median values are most commonly found in the lower fifth of the cloud; above this the median stability slowly increases, although the 25 th percentiles still span neutral stability. This $\delta \theta$ profile shape indicates a layer that is well mixed by cloud-scale circulations, coinciding with a portion of the cloud where negative $S_{w}$ is observed (Fig. 4). In combination, these results indicate that cloudgenerated vertical motions forced by strong but perhaps infrequent downdrafts are active in the lower half of the cloud layer.

Median static stabilities continuously increase with elevation above cloud mid-level $\left(z_{\mathrm{n}}=0.5\right)$ indicating a shift in cloud-layer static stability (Fig. 5a) that is present in both scanning radiometer (black) and radiosounding (blue) profiles. The non-parametric two-sided Wilcoxon rank-sum test computed at $z_{n}=0.2$ and 0.8 indicates the null hypothesis of distributions with equal median is disproved at the $99 \%$ level (thick box-and-whisker distributions in Fig. 5a); the shift in in-cloud median stability with height is a robust feature regardless of variable cloud thicknesses. These results suggest that above $z_{\mathrm{n}}=0.7$, the average cloud layer is embedded within a stable temperature inversion. This is an observed feature unique to AMPS, a regime where cloud top resides above the temperature inversion base, and had been shown to occur more frequently than the traditional temperature-inversion-capped cloud top (Sedlar and Tjernström, 2009; Sedlar et al., 2012) often observed over the subtropical oceans (e.g., Paluch and Lenschow, 1991; Klein and Hartmann, 1993). $S_{w}$ is positive and relatively large within this portion of the cloud embedded within the temperature inversion (Fig. 4). Such shifts in $S_{w}$ and thermodynamic stability suggest that whereas downdrafts are generated from near cloud mid-level, the corresponding downdrafts are absent in the upper third of the cloud. Instead, the portion of cloud above $\sim \mathrm{z}_{\mathrm{n}}=0.7$ shows signatures of only the largest corresponding updraft cycle driven by these clouds.

Static stability of the sub-cloud layer also reveals two distinct layers of stability. Cloud-driven motions penetrate below cloud base into the sub-cloud layer (Fig. 5b), comprising the lower portion of the cloud-driven mixed layer. Statistically, static instability extends below cloud base to approximately half the depth of the sub-cloud layer, marked by a shift in the stability near $z_{\mathrm{n}}=0.4$. Radiosounding static stability distributions are more neutral or slightly stable in the upper half of the sub-cloud layer relative to the scanning radiometer, and in general are in better agreement with the stability distribution profile within the lower half of the cloud layer (Fig. 5a). Thus it appears the instability observed from the scanning radiometer may be overestimated. It is interesting to note that sub-cloud instability weakened, or even became slightly stable, between $z_{\mathrm{n}}=0.9$ and 1.0 relative to $z_{\mathrm{n}}=0.5-0.8$. Local cloud base warming due to net absorption of longwave radiation emitted from below the cloud 

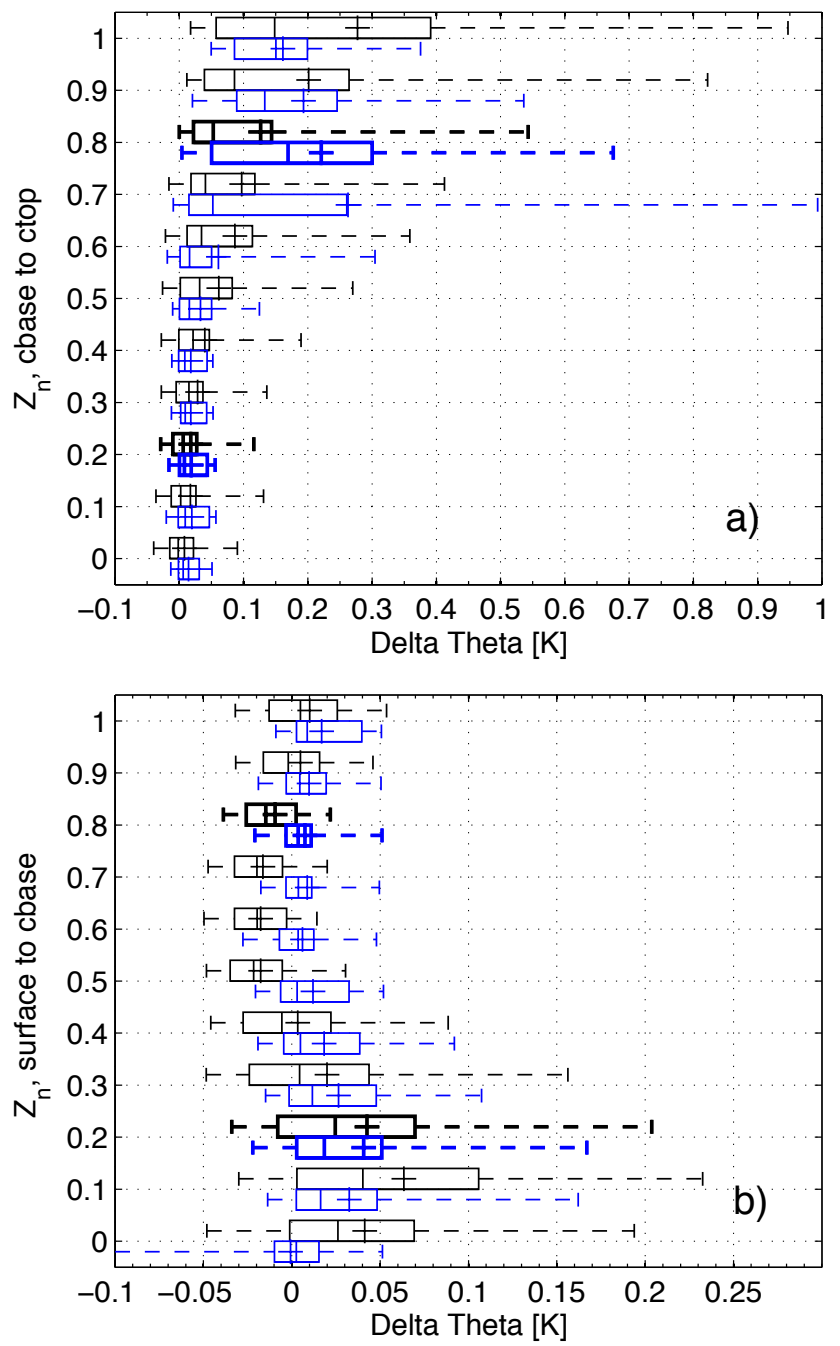

Fig. 5. Box-and-whisker distributions of $\delta \Theta$ derived from $60 \mathrm{GHz}$ scanning radiometer (black) and radiosounding (blue) profiles for (a) in-cloud $\delta \Theta[\mathrm{K}]$ (normalized height profiles where cloud base is $z_{\mathrm{n}}=0$ and cloud top is $\left.z_{\mathrm{n}}=1\right)$ and (b) surface $\left(z_{\mathrm{n}}=0\right)$ to cloud base $\left(z_{\mathrm{n}}=1\right) \delta \Theta$. Data are shown for the full week 25-30 August. Median (vertical lines) and mean (crosses) $\delta \Theta$ within the interquartile boxes and 5-95th percentile (whiskers) distributions are shown. Bold distributions at $z_{\mathrm{n}}=0.2$ and 0.8 in both panels represent statistically significantly different medians at the $99 \%$ level between the two heights using the two-sided Wilcoxon rank-sum significance test; these are shown to indicate significant differences in the median $\delta \Theta$ profile shapes across the normalized layers.

(e.g., Stull, 1988; Paluch and Lenschow, 1991; Harrington et al., 1999) may be responsible for the stability profile change.

Nearer the surface, dominant static stability is observed for both scanning radiometer and radiosounding profiles (Fig. 5b). While the interquartile ranges are large, there is a distinct thermodynamic layer obstructing mixing between the cloud-driven mixed layer and the surface boundary layer about $75 \%$ of the time. This commonly observed decoupled sub-cloud layer has been identified by Shupe et al. (2013) using an independent method relying on $\varepsilon$-profile variations. Cloud-surface decoupling has recently been identified as a frequent feature of AMPS (Solomon et al., 2011; Morrison et al., 2012; Sedlar et al., 2012; Shupe et al., 2013; Sotiropoulou et al., 2014), where lateral advection of heat and moisture appears to play an important role in AMPS persistence. A Wilcoxon rank-sum test of the distributions between $z_{\mathrm{n}}=0.2$ and 0.8 reveal that the transition in median stability within the sub-cloud layer is significant at the $99 \%$ level.

\section{Temporal variance in cloud vertical motions}

We use wavelet spectral analysis (Torrence and Campo, 1998) to identify the dominant scales of variance of incloud $w$ and how it evolves with time. Compared to Fourier analysis, wavelet spectra provide a glimpse into the timefrequency space of a geophysical variable; we also calculate traditional Fourier power spectra in both frequency and wavelength space to complement the wavelet analysis, although these spectra lack the temporal variations and are as such used to sub-sample specific time periods. Time series of cloud-level normalized $w$ variance $\left(w_{\text {norm }}\right)$ are calculated following

$w_{\text {norm }_{i, j}}=\frac{\left(w_{i, j}-\bar{w}_{j}\right)}{\sigma_{w_{j}}}$,

where $i$ and $j$ represent the native $w$ time resolution and cloud level, respectively, and it is $w_{\text {norm }}$ from which we calculate the wavelet time series. Furthermore, wavelet time series are normalized by the peak wavelet power within an observed case and for a particular level within the cloud to facilitate comparisons between other cases and cloud levels. The significance level of the wavelet peaks are calculated relative to a background red-noise spectrum; timescales rejecting the null hypothesis of variance less than the background red noise spectrum are identified (i.e., those periods with variance power that is larger than red noise). The reader is directed to Torrence and Campo (1998) for a detailed explanation on the wavelet analysis method. From these analyses, we can begin to separate the factors (cloud-generated, surface coupling state, large-scale meteorological forcing) that contribute to temporally evolving variance in $w$. Tjernström and Mauritsen (2009) analyzed the time-frequency space of large-scale meteorological forcing during a 2001 campaign within the central Arctic; they found mesoscale variability to be most dominant on timescales longer than $30 \mathrm{~min}$, often observed on timescales of 1-3 h. Thus, when analyzing the time variability of in-cloud $w$, we consider variances on timescales longer than $30 \mathrm{~min}$ to be independent of clouddriven forcing and instead related to changing larger scale meteorology, on the mesoscale or larger.

Motivated by distinct differences in the velocity skewness and potential temperature gradient profiles across the 
cloud layer (Figs. 4-5), wavelets are analyzed at three levels within the cloud layer: near cloud top $\left(z_{\mathrm{n}}=0.8\right)$, cloud middle $\left(z_{\mathrm{n}}=0.5\right)$ and cloud base $\left(z_{\mathrm{n}}=0.2\right)$. The focus is on two case periods during the week of 25-30 August at ASCOS; we begin each case period with a description of the larger-scale meteorological conditions (cloud boundaries, thermodynamics, evidence of changing mesoscale weather conditions and the surface-cloud coupling state). Emphasis is placed on characterizing the primary cloud-driven frequency scales of $w$ relative to the surface-cloud layer thermodynamic $(\Theta)$ and dynamic $(\varepsilon)$ coupling states present and on the vertical coherency of such frequencies across the cloud layer.

\subsection{Case I: 00:00-17:00 UTC, 28 August}

The cloud-layer profile of $S_{w}$ during this case is shown in the upper panel of Fig. 6. Positive $S_{w}$ in the upper third, overlaying negative $S_{w}$ below, is present for the majority of the period. Initially, cloud base and top vary between 400 and $550 \mathrm{~m}$ and between 800 and $900 \mathrm{~m}$, respectively. Between 05:00 and 06:30 UTC (all times given as UTC), there is a shift in the cloud structure with both base and top rising approximately $300-400 \mathrm{~m}$ in conjunction with a low-level jet (LLJ) at $700 \mathrm{~m}$; following the increased cloud height, cloud thickness decreases by approximately $100 \mathrm{~m}$. Thermodynamic profiles (Fig. 6, lower panels) show an increase in both equivalent potential temperature $\left(\Theta_{\mathrm{e}}\right)$ and specific humidity below $1600 \mathrm{~m}$, suggesting the rising cloud layer is connected with a change in air mass occurring after 06:00. Initially, a constant equivalent potential temperature $\left(\Theta_{\mathrm{e}}\right)$ profile (00:00 sounding) in the layer between cloud and surface indicates a well-mixed, coupled layer. By 06:00, the $\Theta_{\mathrm{e}}$ profile suggests a weaker thermodynamic coupling. Clouddriven mixed-layer base heights estimated from $\varepsilon$ profiles corroborate a general surface-cloud coupling until approximately 06:00 (Fig. 6 top panel). Coinciding with cloud rising, the cloud-driven mixed-layer base also rises, revealing a decoupling from the surface layer. A distinct stable layer below $350 \mathrm{~m}$ emerges in the 12:00 profile, indicating a transition during mid-morning from a coupled to decoupled cloudsurface system. Cloud-driven mixing, however, continues below cloud base down to the elevation where the stable layer emerges. $\mathrm{RH}_{\text {ice }}$ indicates a relatively dry sub-cloud layer where cloud-driven circulations are penetrating, suggestive of warm air advection (see $\Theta_{\mathrm{e}}$ profile). This case allows for an analysis of how $w$-variance timescales are impacted by a transition between surface and cloud layer stability, addressing fundamental question 2 proposed in Sect. 1.

Time-evolving wavelet power spectra for cloud-level $w$ are characterized in the left panels of Fig. 7. The wavelets indicate an array of significant variance timescales for the three cloud levels, ranging from hours down to minutes. Although a general coherency in the peak wavelet timescales across the cloud levels is present, occasionally significant peak timescales are incoherent (e.g., $w$ variance between

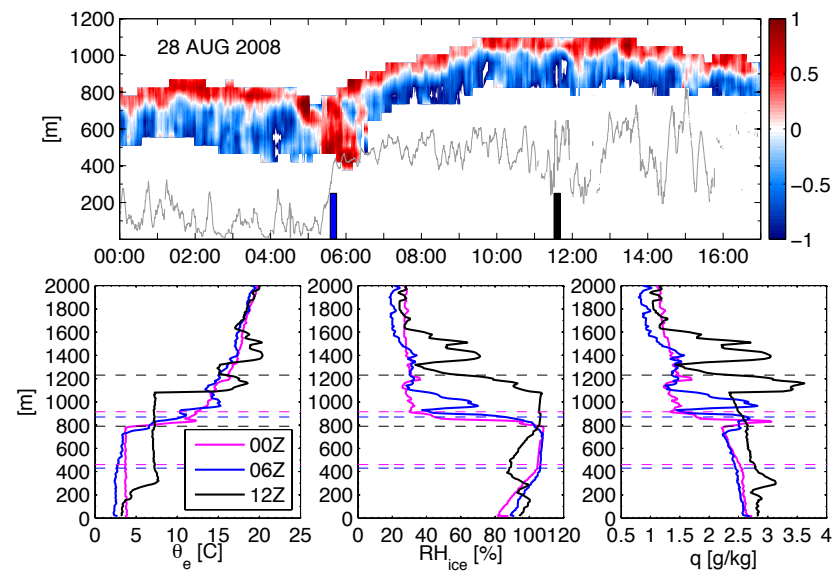

Fig. 6. Upper panel: $S_{w}$ (contours) within the low-level AMPS between 00:00 and 17:00 UTC on 28 August. The gray line indicates the base of the cloud-driven mixed layer derived from $\varepsilon$ profiles. Lower panels: thermodynamic profiles of equivalent potential temperature $[\mathrm{C}]$, relative humidity with respect to ice $[\%]$ and specific humidity $\left[\mathrm{g} \mathrm{kg}^{-1}\right.$ ] from radiosoundings released at respective times (the vertical bars in the upper panel indicate the respective radiosonde release times; the 00:00 UTC (magenta) sounding was released just prior to the start of this period). Included in the lower panels are the ceilometer-radar-derived cloud base and top heights at the respective radiosonde time (dashed lines).

03:00 and 07:00 on the timescale of hours). Therefore, it is useful to understand the relationship between thermal stability and meteorological forcing with cloud $w$ variability to help explain similarities and differences across the cloud layer.

Dominant scales of variability reoccurring at $2-15$ min frequency are observed throughout the cloud from 00:00 to 5:00 UTC, when the surface and cloud layer are coupled (Fig. 6). Here, both updrafts from the surface and downdrafts generated by the cloud layer are intimately connected. Shortly after 05:00, and persisting until about 07:00, the wavelets indicate a minima in power at all cloud levels for frequencies faster than about $40 \mathrm{~min}$ as the cloud layer ascends. The longer timescale contribution at cloud base and top are also suggested by the statistically significant wavelet peaks at the $\sim 1-3 \mathrm{~h}$ frequencies during this active transition period (Fig. 7a and c). The change in frequency timescales from relatively fast to slow suggests that this transition is forced more by mesoscale motions than by changes in cloud-driven $w$, consistent with the analysis above indicating an air mass change. The shift towards slower, mesoscaledominated circulation timescales is not long-lived. As clouddriven mixed-layer depths and thermodynamic profiles indicate a transition towards surface-cloud decoupling after 06:00 (Fig. 6), variance peaks on the 4-15 min frequency range reemerge at all cloud levels shortly after 09:00. Here, only the cloud-generated buoyant motions are captured in the analyses, as vertical motions originating from the surface 

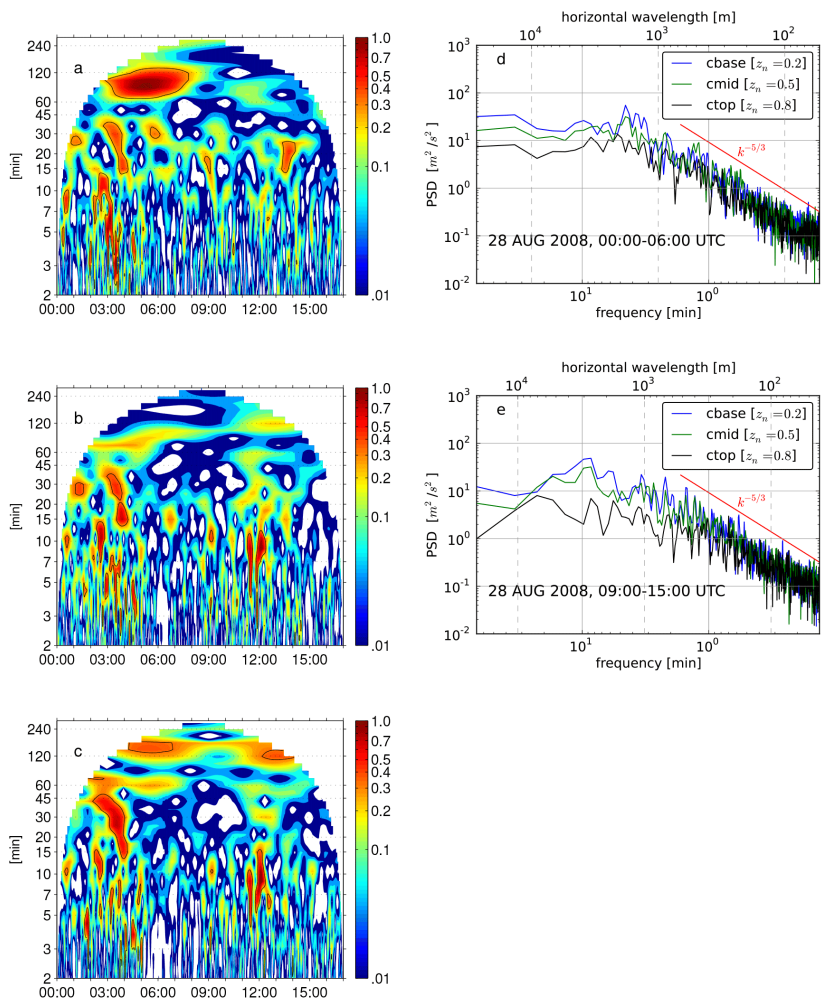

Fig. 7. Normalized $w$ wavelet evolution (contours, 1 is maximum observed $w$ variance; note logarithmic color scale) as a function of frequency scale (ordinate [min]) for 00:00-17:00 UTC on $28 \mathrm{Au}-$ gust (hours, abscissa) for (a) cloud top $\left(z_{\mathrm{n}}=0.8\right)$, (b) cloud middle $\left(z_{\mathrm{n}}=0.5\right)$ and (c) cloud base $\left(z_{\mathrm{n}}=0.2\right)$. Wavelet spectral peaks that are statistically significantly ( $98 \%$ confidence level) different than the theoretical red-noise background spectrum, calculated using the lag1 autocorrelation coefficients, have black contour lines. The right panels show the absolute (non-frequency scaled) power spectral density (PSD) of cloud-level (colors) $w\left[\mathrm{~m}^{2} \mathrm{~s}^{-2}\right]$ as a function of frequency (lower axis [min]) and effective horizontal wavelength (upper axis [m]) for subsets of the case period: (d) 00:0006:00 UTC and (e) 09:00-15:00 UTC.

boundary layer are disconnected from the cloud. While the peak temporal frequency ranges are very similar to the clouddriven overturning timescales observed during the first $6 \mathrm{~h}$ of the period when cloud and surface are coupled, there is a tendency for slightly increased intermittency in the peak wavelet variances during the second half of this period relative to the first. This is especially true for $w$ variance occurring near cloud top (Fig. 7a).

To further separate the impacts of surface-cloud stability on vertical motion timescales (fundamental question 2 from Sect. 1), linearly detrended cloud-level $w$ power spectra, as a function of both frequency and horizontal wavelength, are shown in Fig. 7 for two sub-sampled time periods: 00:0006:00 (d) and 09:00-15:00 (e). Note that we only present frequencies faster than approximately $60 \mathrm{~min}$ to focus on the absolute power of the cloud-driven circulation timescales. The
$-5 / 3$ slope at the high-frequency end of these spectra indicate that we capture the inertial subrange cascade of turbulent energy from slower to faster timescales; these spectra agree strikingly well with an independent method of estimation (Shupe et al., 2012). During 00:00-06:00, when the surface and cloud were thermodynamically coupled, nearly all cloud levels indicate local maxima at frequencies lower than the inertial subrange, dominated by those between 4 and $6 \mathrm{~min}$ (Fig. 7d), with the slower peak occurring near cloud top. Corresponding horizontal wavelength scales for these peak frequencies, calculated using the mean cloud-layer wind speed from radiosondes (e.g., Shupe et al., 2008a), range between 1800 and $2000 \mathrm{~m}$.

When the surface and cloud become decoupled (09:0015:00), spectral peaks broaden and frequencies slow to near $9 \mathrm{~min}$, and horizontal wavelengths increase to near $2700 \mathrm{~m}$ (Fig. 7e). These frequency and wavelength changes are less obvious near cloud top, except for a distinct decrease in the now-broadened spectral peak magnitudes observed between the two coupling states. Physical layer depths between clouddriven mixed-layer base and cloud mid-level for the full period (00:00-17:00) are primarily between 500 and $700 \mathrm{~m}$ (Fig. 6), while the derived horizontal wavelengths are approximately 3 times as large, regardless of coupling state. A large anisotropy between cloud-driven horizontal and vertical eddy wavelengths is apparent, with vertical motions often being much shallower.

Fundamental question 3 stated in Sect. 1 aims to address the coherency of vertical motions across the cloud layer. It is apparent that the spectral densities coming from velocity variations at cloud base and mid-levels are larger than that at cloud top. The absolute peaks in spectral density for cloud base and mid-levels are similar to each other during the two different coupling states, and it is only the change in peak frequency that differs (Fig. 7d and e). These results indicate peak $w$ variance is not forced by motions originating at the surface but instead controlled by the buoyant production within the cloud layer. However, for cloud top the velocity power spectra tend to decrease more during the transition from a coupled to decoupled state, suggesting differences in the vertical motion characteristics. These results agree with a slight enhancement of cloud-driven circulation frequency when a thermodynamic coupling with the surface is present. It is important to note that mean LWPs for the sub-sampled periods - 77 and $82 \mathrm{~g} \mathrm{~m}^{-2}$, respectively - are not significantly different; the change in cloud-driven overturning circulation frequency, although slower during the decoupled period, is still sufficient at generating mixing and producing cloud condensate.

\subsection{Case II: 00:00-20:00 UTC, 29 August}

Case II represents a low-level AMPS impacted by advection of upper-level cloud layers overhead. Initially, the low-level cloud is the only cloud layer; after approximately 03:00 an 


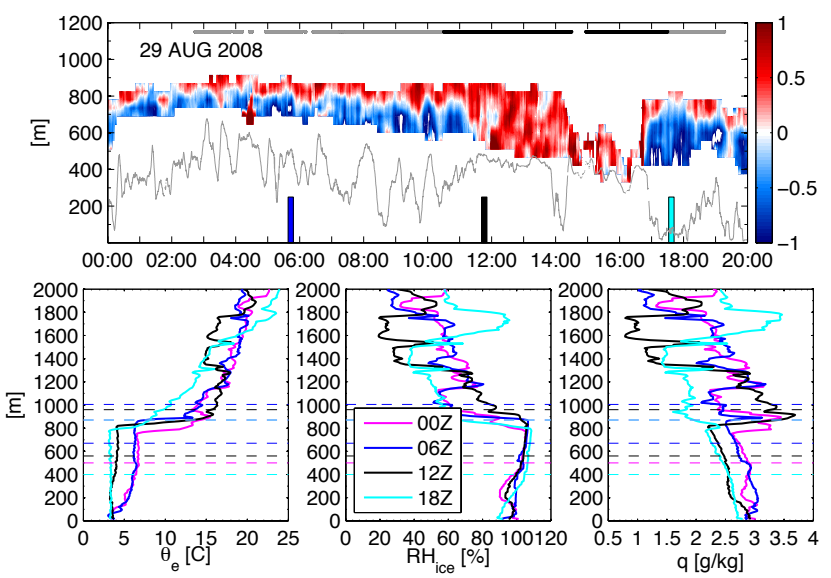

Fig. 8. Same as in Fig. 6 but for the period 00:00-20:00 UTC on 29 August. The 00:00 UTC radiosounding was released just prior to the start of this period, and its release time is not indicated by a magenta bar in the upper panel. Times when an upper-level cloud above $5 \mathrm{~km}$ are present is indicated by the dots in the upper panel; gray dots indicate times when upper cloud radar signatures are suggestive of ice-only hydrometeors, while black dots represent times when liquid hydrometeor signatures are observed in the upper cloud radar profiles.

intermittent cirrus above $9000 \mathrm{~m}$ advects overhead, continuing to increase in thickness up to $4000 \mathrm{~m}$, all the while with a descending base downwards to $4000 \mathrm{~m}$ by 12:00 (see Fig. 1). By 14:30, the upper cirrus advects on, and a second low-level cloud spanning 1200-2000 m advects over the original lowest cloud layer. Around 15:00, another cirrus with base at $8000 \mathrm{~m}$ emerges and remains overhead until 19:00; meanwhile the mid-level cloud between 1200 and $2000 \mathrm{~m}$ a.g.l advects past ASCOS by 17:00 (Fig. 1).

$S_{w}$ of the lowest AMPS under this array of overhead sky conditions is shown in Fig. 8 (top panel). Positive $S_{w}$ near cloud top overlaying negative values is present during the first $12 \mathrm{~h}$. Positive $S_{w}$ and a deeper cloud layer emerge between 12:00 and 14:00, coincident with the gradually lowering base of this cloud and the deepening upper cirrus. By 14:15, the mid-level cloud between 1200 and $2000 \mathrm{~m}$ advects over the thinning and tenuous lowest layer (Fig. 8). Not until this second cloud layer advects past does the lower layer revamp itself and show a deepening cloud thickness with increases in both base and top heights. Thermodynamic profiles indicate a transition from a decoupled surface and cloud layer (00:00, 06:00, 12:00 soundings) to a fully coupled system by 18:00 (Fig. 8, lower panels). The cloud-driven mixedlayer base height suggests that coupling was brief between 17:00 and 18:30, varying between decoupled and coupled thereafter (Fig. 8, top panel).

Responses in cloud velocity wavelets (Fig. 9) very clearly follow the changing cloud conditions above the low AMPS. Prior to 09:00, there are many velocity wavelet peaks occurring coherently at all three cloud levels on timescales shorter than $\sim 20$ min (Fig. 9a-c); intermittent wavelet peaks on mesoscale timescales (> $30 \mathrm{~min}$ ) are also present at each cloud level. After 09:00 and until mid-afternoon, there is a striking decrease in spectral density at the cloud-driven timescales $(<20 \mathrm{~min})$, coinciding with the increasing cirrus thickness and lowering base. By 11:00, and onwards until nearly 17:00, the AMPS cloud base continuously drops, with a clear indication of positive $S_{w}$ across the entire cloud (Fig. 8). Mixed-layer base heights suggest much of this period to be a decoupled cloud-surface system; however there are indications in the noon radiosonde of potential neutral static stability originating from the surface upwards to a few hundred meters (Fig. 8); it is possible that the cloud-driven mixed layer may have connected with boundary-layer turbulence during this time. In-cloud wavelet peaks, however, remain dominated by timescales longer than $20 \mathrm{~min}$ (Fig. 9ac), consistent with a reduction in cloud-driven circulations (2-20 min) via reduced cloud-top longwave cooling. As the longwave opacity of the atmosphere above the low AMPS increases, a reduction in radiative divergence near cloud top ensues (radiative shielding, e.g., Rogers et al., 1985). Radiative shielding appears to become even more dominant as the midlevel cloud advects overhead, causing the lowest AMPS layer to become thin and tenuous. Although the tenuous cloud between 14:00 and 16:30 is masked from the wavelet analysis, due to multiple mixed-phase cloud layers below $2.5 \mathrm{~km}$, $S_{w}$ is positive across the whole cloud layer from as early as 11:00 (Fig. 8), suggesting that cloud-generated downdrafts driven by cloud-top cooling are in fact suppressed by radiative shielding from cloud layers above.

After the second low-level cloud passes $(\sim 16: 45)$, the lowest AMPS responds immediately, with increases in base and top heights (Fig. 8), cloud thickness and LWPs, from approximately 20 to $120 \mathrm{~g} \mathrm{~m}^{-2}$, in less than $15 \mathrm{~min}$. At the same time, velocity wavelets indicate a reemergence of faster, cloud-driven timescales between 3 and $17 \mathrm{~min}$ at all cloud levels similar to those occurring during the morning hours when cloud and surface were decoupled (Fig. 9a-c). Coincidently, thermodynamic profiles and cloud-driven mixedlayer depths indicate ongoing cloud-surface coupling at the same time negative $S_{w}$ is observed over much of the cloud layer, indicative of negative buoyancy production associated with efficient cooling near cloud top (Hogan et al., 2009).

Temporal and horizontal scales of motion for three $3 \mathrm{~h}$ sub-periods corroborate the impacts of radiative shielding on the low-level AMPS. Distinct spectral maxima related to cloud-driven variability are evident during both the decoupled (03:00-06:00, Fig. 9d) and intermittently coupled (17:00-20:00, Fig. 9f) time periods. Spectral peaks are near the 5-7 min frequency range for all cloud levels during the decoupled morning and increase to near 2-5 min during the coupled evening hours, albeit with broader spectral maxima. A feature observed during the latter coupled period that is missing during the morning decoupled period is a local spectral peak at the 10-20 min range for both cloud middle and 

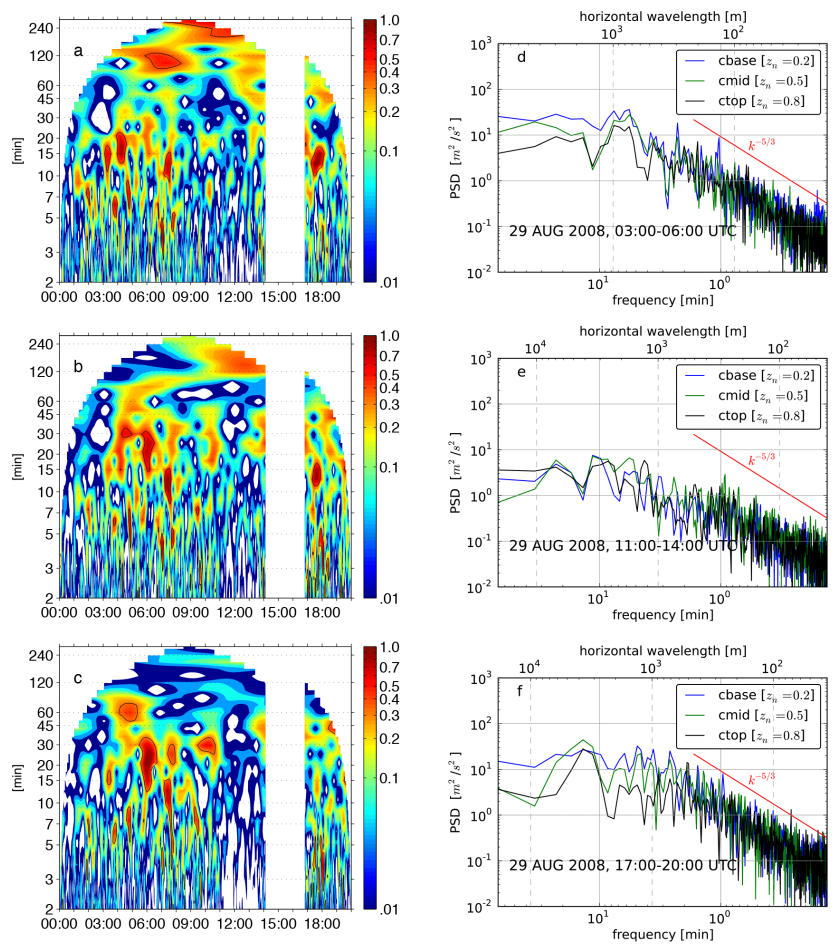

Fig. 9. Same as in Fig. 7, but for 00:00-20:00 UTC on 29 August. Data between 14:15 and 16:50 UTC are masked as there were two low-level clouds below $2.5 \mathrm{~km}$ during this time range. The right panels show the absolute (non-frequency scaled) power spectral density (PSD) of cloud-level (colors) $w\left[\mathrm{~m}^{2} \mathrm{~s}^{-2}\right]$ as a function of frequency (lower axis [min]) and effective horizontal wavelength (upper axis [m]) for subsets of the case period: (d) 03:00-06:00, (e) 11:0014:00 and (f) 17:00-20:00 UTC.

top levels (Fig. 9f). Interestingly, due to a change in horizontal wind speed, calculated horizontal wavelengths ranging between 700 and $1000 \mathrm{~m}$ associated with cloud-driven spectral peaks are similar between the two periods with different coupling states. The aspect ratio between vertical distance of cloud mid-level and mixed-layer base height (top panel in Fig. 8) with horizontal wavelengths are closer to 1.5 to 2, compared to near 3 that was observed for case I.

Strikingly different velocity power spectra occur between 11:00 and 14:00 (Fig. 9e) as the lowering cirrus base reaches $4 \mathrm{~km}$ and Doppler radar moments suggest potential for liquid droplets in this upper cloud; radiative shielding likely causes changes in cloud-driven $w$ variability relative to the other two periods. In general, the frequency range for spectral peaks increases to $8-12 \mathrm{~min}$, with a decrease in power by an order of magnitude for the cloud-driven turbulent timescales compared to the other two periods (Fig. 9e).

\subsection{Synopsis of both case studies}

In general, both case studies reveal similarities in the processes impacting vertical velocity variance timescales. The relative consistency in peak power spectra timescales and magnitudes between coupled and decoupled states suggests the dominant overturning forcing is a result of the cloud layer TKE and not from the surface. The decreased spectral density variance across the cloud during enhanced radiative shielding (Fig. 9e) further supports the conclusion of cloudgenerated buoyancy as the primary forcing. Velocity characteristics near cloud top differ in magnitude to those near cloud mid- and base levels (fundamental question 2). The relationship of cloud top with the stable temperature inversion correlates with reduced $w$ variance in the upper portion of the cloud (fundamental question 1); such a reduction appears even more enhanced when the cloud and surface are thermodynamically decoupled (fundamental question 3 ). This conclusion suggests a modification on the coherency of vertical motion between cloud levels dependent upon coupling state.

\section{4 w covariance between cloud levels}

Using the wavelet time series for each cloud level, we address fundamental question 2 and 3 from Sect. 1 by calculating the correlation between vertical motions at different levels within the cloud following

$r(t, T)=\mathcal{R}\left[\frac{\operatorname{cov}\left(w_{1}, w_{2}\right)}{\left(\sigma_{w_{1}}^{2} \cdot \sigma_{w_{2}}^{2}\right)^{1 / 2}}\right]$,

where $r$ is the correlation coefficient as a function of time $(t)$ and frequency period $(T)$, and $\mathcal{R}$ represents the real part of the complex solution of covariance (cov) of $w$ (subscripts represent $w$ at two different cloud levels) weighted by the product of $w$ variance at the two levels. Results are shown for the sub-sampled periods during the two cases on 28 August (Fig. 7) and 29 August (Fig. 9), when both thermodynamic $\left(\Theta_{\mathrm{e}}\right.$ profiles) and dynamic ( $\varepsilon$-derived cloud mixed-layer estimates) coupling and decoupling between cloud and surface occur.

Figure 10 shows the median and quartile range of the correlation coefficients of $w$ between cloud middle and top (left panels a, d), middle and base (middle panels b, e) and base and top (right panels $\mathrm{c}, \mathrm{f}$ ) as a function of frequency. The general pattern in Fig. 10 indicates that median correlations between levels are weakest at timescales below $2 \mathrm{~min}$, and the quartile spreads are also largest at these higher frequencies. At timescales longer than $4 \mathrm{~min}$, the median correlations are generally above 0.8 for cloud middle and top (a, d) and middle and base (b,e); recall that peak variances in the velocity spectra occur in the range between 2 and $9 \mathrm{~min}$. At timescales longer than $20 \mathrm{~min}$, the correlations become variable. Correlations between vertical motions at cloud base-and-top (c, f) show similar changes with frequency, but the absolute correlations are generally lower than for adjacent cloud levels.

Distributions of $r$ values for coupled (blue lines and shading) and decoupled (red lines and shading) cloud-surface states exhibit a qualitatively similar pattern as a function 

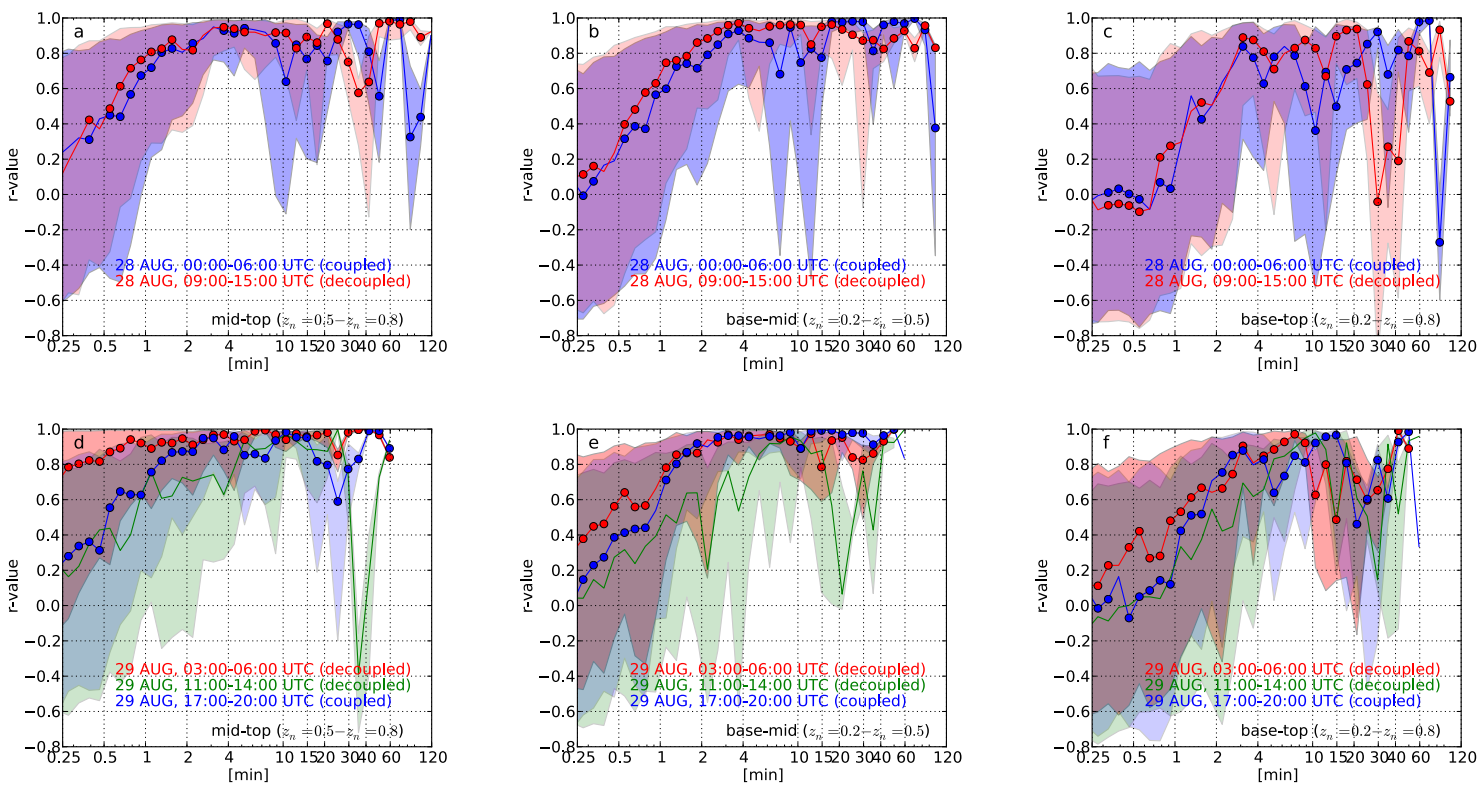

Fig. 10. Median (lines) and interquartile range (shaded) of correlation coefficients ( $r$ values) for $w$ between cloud middle-to-top levels (left), cloud middle-to-base levels (middle) and cloud base-to-top levels (right) as a function of wavelet temporal frequencies calculated using Eq. (4). (a-c) are for sub-sampled periods during 28 August: 00:00-06:00 UTC (blue) and 09:00-15:00 UTC (red). (d-f) are for subsampled periods on 29 August: 03:00-06:00 UTC (red), 11:00-14:00 UTC (green) and 17:00-20:00 UTC (blue); text in each panel indicates the sub-sampled time range and surface-cloud coupling state. Filled circles indicate median $r$ values at the respective frequency that are statistically significantly different between the sub-sampled time periods at the $98 \%$ confidence level using a double-sided Wilcox rank-sum statistical test.

of frequency (Fig. 10). On timescales shorter than $20 \mathrm{~min}$, median $w$ correlations between cloud middle and top (a, d) and middle and base $(b, e)$ during thermodynamically decoupled cases are almost always slightly larger and less negatively skewed than those during coupled cases; these differences are also statistically significant. The exception is during the decoupled sub-sampled period of 11:00-14:00 on 29 August (Fig. 10d-f, green), when radiative shielding from a mid-level cloud leads to a reduction in $w$ covariance between cloud levels of the lower AMPS relative to the other sub-sampled periods. These results indicate that coupling with the surface actually tends to slightly reduce the vertical coherency in $w$ between adjacent cloud levels. It is possible that additional turbulent motions originating from the cloud mixed-layer connection with boundary-layer turbulence cause the changes in $w$ covariance between adjacent levels. Furthermore, even though the median $r$ values in $w$ between cloud base-and-top (Fig. 10c, f) are weaker than the adjacent levels $(a-b, d-e)$, they are still positive, and therefore coherent, for the timescales between 2 and $20 \mathrm{~min}$. This is an interesting result considering the different thermodynamic stability and $w$-skewness profiles observed near cloud top relative to lower within the cloud. The coherency here may be related to the modeling results of Solomon et al. (2011). Those authors found the weaker vertical motions in the layer of cloud residing within the temperature inversion were related to sustained production of condensate rather than producing buoyant cloud-scale overturning. Evidence of a commonly observed saturated inversion layer (Devasthale et al., 2011; Nygård et al., 2014) near AMPS cloud top (Solomon et al., 2011; Sedlar and Tjernström, 2009; Sedlar et al., 2012) further supports the notion of cloud persistence through an elevated moisture inversion source, especially when the surface and cloud are in a decoupled state.

\section{Coupled vs. decoupled cloud-surface characteristics}

Coupling between surface and cloud occurs intermittently, although a thermodynamic decoupling is most frequent (Shupe et al., 2013; Sotiropoulou et al., 2014). Sub-sampling the case periods above has shown differences in both timeevolving $w$ and cloud-generated peak variance timescales depending upon the coupling state. Here the distributions of $w$ variance at cloud levels are examined for coupled and decoupled cases for the full period, 25-30 August, using the $\varepsilon$-derived cloud mixed-layer depths (Shupe et al., 2013). Cumulative frequency distributions (CFDs) of cloud-level $w$ variance for four frequency ranges are shown in Fig. 11. The shapes of cumulative frequency distribution are similar across cloud levels. However, differences emerge in the magnitude of $w$ variance depending upon location within cloud and surface-cloud coupling state. The increasing slopes of 
the CFDs towards unity are generally steeper (indicating an increased contribution from smaller variances) moving vertically upwards from cloud base (Fig. 11c) to cloud top (Fig. 11a). Decreased variance with cloud height also tends to be larger during the coupled surface-cloud state (solid lines) relative to the decoupled state (dashed). Such decreases with cloud height tend to be larger for the longer frequency ranges (magenta and black) compared to the shorter frequency ranges (blue and green).

Considered together, the CFDs show a decrease in $w$ variance the upper portion of cloud layer for all timescales (Fig. 11a). Only a slight decrease in $w$ variance for the four frequency ranges occurs when moving upwards from near cloud base to cloud middle (Fig. 11b-c), indicating a coherent structure in $w$ across these levels (fundamental question 3). During decoupling, the distributions of $w$ variance are modestly similar for both cloud base and mid-levels at the three frequency ranges slower than $2 \mathrm{~min}$ (the cloudgenerated frequencies) relative to times of coupling. This result further supports the conclusion that the dominant forcing of vertical velocity within the cloud layer is generated by the cloud itself.

In Fig. 12, 2-D histograms show the relationship between $w$ variance at cloud mid-level for the 5-10 min frequency range (see Fig. 11) and scaled LWP (LWP scaled $_{\text {) }}$. We use $\mathrm{LWP}_{\text {scaled }}=\mathrm{LWP} / \Delta z$ rather than LWP because LWP is dependent upon both the actual cloud condensate as well as the cloud thickness, and it therefore inversely includes changes in LWP due to cloud thickness $(\Delta z)$. These relationships suggest that, for the decoupled cases (Fig. 12d), smaller LWP $_{\text {scaled }}$ are associated with a dominance of weaker $w$ variances compared to coupled cases (Fig. 12c), which have a very dominant peak in $\mathrm{LWP}_{\text {scaled }}$ distribution near $0.2 \mathrm{~g} \mathrm{~m}^{-3}$ (Fig. 12c). Two-dimensional histograms for the other three frequency ranges analyzed in Fig. 11 have similar distributions and are thus not shown. Relative frequency distributions (RFDs) of cloud thickness (Fig. 12a) and LWP (Fig. 12b) are shifted slightly towards geometrically and optically thinner clouds for the decoupled compared to coupled cases. In combination, these results suggest the reduction in $\mathrm{LWP}_{\text {scaled }}$ for decoupled cases, which are weighted by slightly smaller cloud thicknesses (Fig. 12a), is controlled by a reduction in the LWP production rather than the presence of thicker clouds.

In coupled cases, turbulence generated near the surface may also play a role. Higher $w$ variance has been observed in coupled cases, possibly as a result of interactions between the cloud-driven turbulence and turbulence generated near the surface through buoyancy and/or mechanical mixing emerging from vertical wind speed shear. To further examine the latter, wind speed profiles from radiosonde releases during 25-30 August (18 total profiles) are normalized individually by the maximum observed wind speed between the surface and cloud top, and normalized in height for layers with common mixing-state characteristics between the cou-
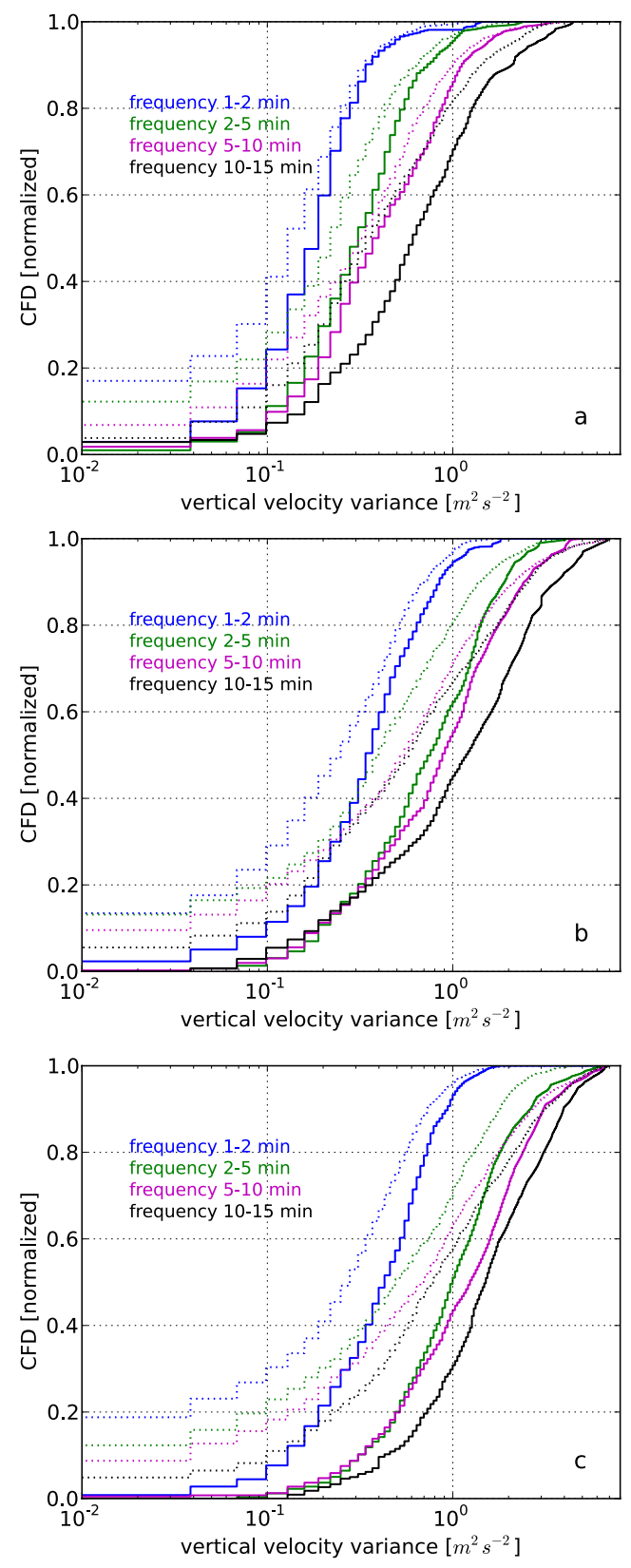

Fig. 11. Normalized cumulative frequency distributions (CFDs) of $w$ variance $\left[\mathrm{m}^{2} \mathrm{~s}^{-2}\right]$ at (a) cloud top level, (b) cloud mid-level and (c) cloud base level for coupled (solid) and decoupled (dashed) surface-cloud states during 25-30 August. CFDs are separated into four frequency ranges: 1-2 min (blue), 2-5 min (green), 5-10 min (magenta) and 10-15 min (black). A 15 min running average has been applied to the $w$ variances.

pled (Fig. 13, left panels) and decoupled (Fig. 13, right panels) cases: cloud base to top (Fig. 13a, b), the active mixing layer below cloud base (Fig. 13c, d) and the stable, decoupled layer between the surface and mixed-layer base height (Fig. 13e). The mean profiles indicate the frequent presence of local wind speed maxima in the lower portion of the cloud 

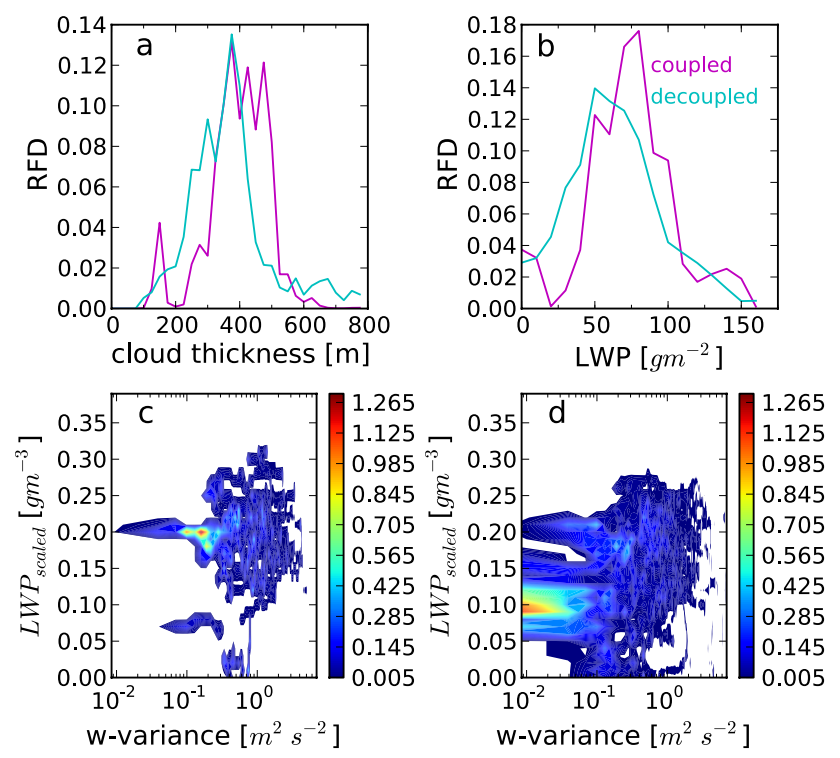

Fig. 12. Relative frequency distributions (RFDs) of (a) cloud thickness [m] and cloud LWP $\left[\mathrm{g} \mathrm{m}^{-2}\right]$ for coupled (magenta) and decoupled (cyan) surface-cloud coupling states during 25-30 August. Two-dimensional RFD histogram (contours) relationships between cloud-layer scaled LWP $\left[\mathrm{g} \mathrm{m}^{-3}\right.$ ] (see text for description) and $w$ variance in the 5-10 min frequency range at cloud mid-level for (c) coupled and (d) decoupled states.

layer (Fig. 13a) and upper portion of the cloud-driven mixed layer (Fig. 13c) for coupled cases. The local wind maximum near cloud base appears to be connected to increased momentum at cloud level transferred downward into the sub-cloud mixed layer in connection with the coupling between cloud and sub-cloud layers. The wind speed shear that emerges moving down within the mixed layer may also enhance the coupling between cloud and surface via mechanical mixing.

Statistics on the normalized wind profiles for decoupled cases show substantial variability in the individual profiles and therefore a distinct local maximum in wind speed is difficult to find. However, the decoupled wind profiles suggest the potential for increased wind speeds near the cloud midlevel (Fig. 13b), but mean vertical wind speed shear is absent within the mixed layer (Fig. 13d). Thus momentum may potentially be transferred down from the cloud layer, where it appears to be sufficiently mixed throughout the cloud-driven mixed layer. Wind speed shear is present between the surface and mixed-layer base (Fig. 13e), but this shear alone is not able to mix across the decoupling interface between clouddriven vertical mixing and turbulent mixing nearer the surface, maintaining a decoupled state. Mean wind speed profiles just above and below cloud base are significantly different at the $90 \%$ confidence level (Fig. 13c-d, red stars), suggesting that the local wind speed maximum near cloud base is robust during fully coupled cases but absent during the decoupled cases. These results suggest the presence of
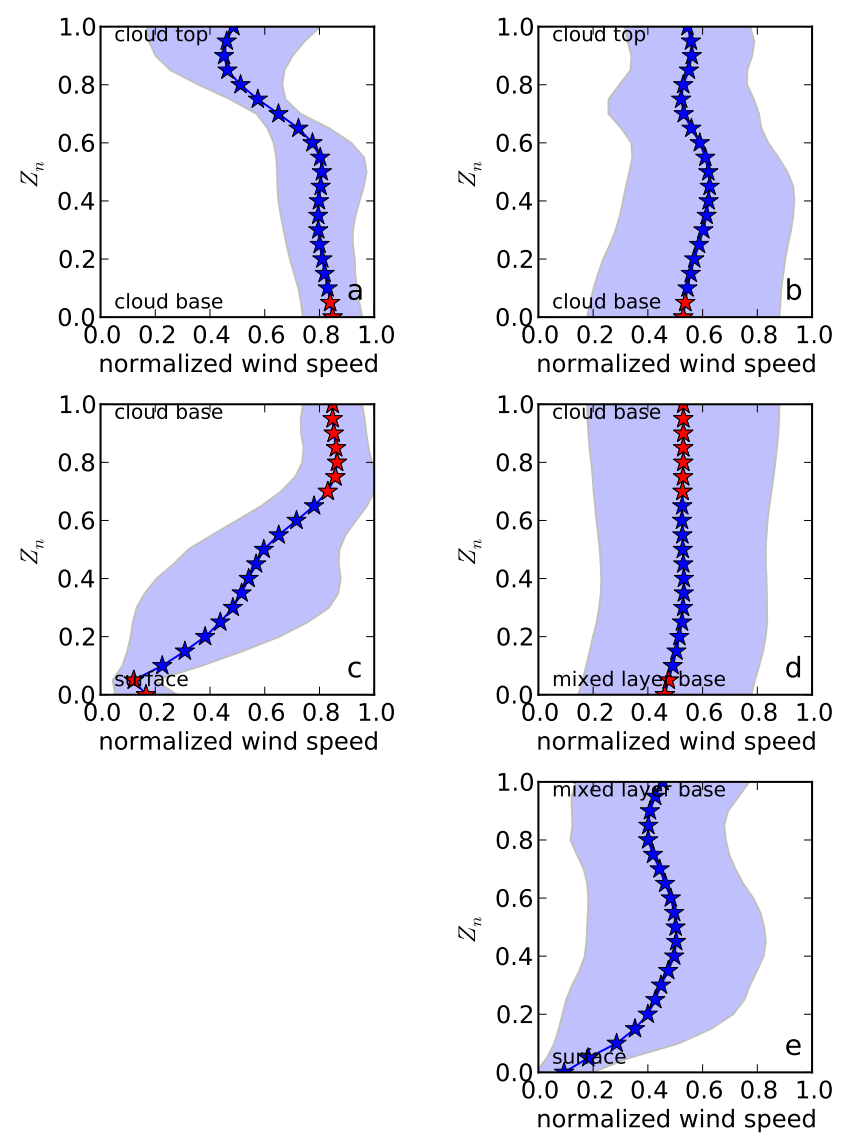

Fig. 13. Mean (starred line) and standard deviation of radiosonde wind speeds normalized by maximum wind speed between surface and cloud top and normalized in height by layer boundaries: (a-b) cloud base $\left(z_{\mathrm{n}}=0\right)$ to cloud top $\left(z_{\mathrm{n}}=1\right)$, (c-d) sub-cloud mixedlayer to cloud base and (e) surface to mixed-layer layer base; physical height boundaries are labeled on the left of each panel. Left panels are sub-sampled for coupled surface-cloud systems and right panels for decoupled surface-cloud systems between 25 and $30 \mathrm{Au}-$ gust. Red stars indicate mean values between coupled and decoupled cases that are statistically significantly different at the $90 \%$ confidence interval following a double-sided Student $t$ test.

mechanical wind speed shear mixing, or lack thereof, may enhance the surface-cloud coupling state and potentially be one of the reasons for the observed increases in $w$ variance when the surface and cloud are coupled (Fig. 11).

\section{Discussion}

Using wavelets to identify temporally varying $w$ timescales, we find the vertical coherency of in-cloud motions tends to respond to outside factors not explicitly determined by the cloud layer, such as synoptic- or mesoscale forcing and the presence of cloud layers aloft. In particular, when mesoscale meteorological variations are ongoing, such as during the morning of 28 August, in-cloud $w$ variability tends to be 
dominated by longer timescales (> $30 \mathrm{~min}$ ) presumably associated with large-scale changes in atmospheric thermodynamics and variable wind shifts (Tjernström and Mauritsen, 2009; Tjernström et al., 2012). During 29 August, wavelets and power spectra of $w$ clearly indicate changes associated with the presence, or absence, of mid-level clouds above the lower AMPS layer; advection of cloud layers overhead is shown to result in near-instantaneous responses in cloud LWP and $w$ skewness profiles. These results indicate a direct link between the efficiency of buoyancy production through cloud longwave cooling (radiative shielding when multiple cloud layers are present) and the dominant timescales associated with the cloud-driven overturning motions. Thus, the generation of vertical motions by the cloud layer has a distinct correlation with the efficiency of cloud condensate (LWP) production/dissipation (Shupe et al., 2008a), which in turn appears to be correlated with the strength and timescale of vertical motion variability.

When the cloud-surface system is fully coupled, power spectral analysis indicates peak cloud $w$ variability tends to occur at timescales on the order of 2-6 min. Timescales have a tendency to modestly decrease towards 5-9 min during decoupled cloud-surface cases; however, due to slower winds, estimated wavelengths associated with these peaks only slightly increase. These ranges of cloud $w$-variance timescales agree well with those from Barrow, Alaska, during autumn 2004 (Shupe et al., 2008a) and independently from the same ASCOS time period (Shupe et al., 2012, 2013). The similarity in both time and horizontal scales between coupled and decoupled states suggests the dominant forcing for all cases is generated from the cloud layer; the surface forcing appears to be weak (e.g., Shupe et al., 2013; Sotiropoulou et al., 2014), such that it does not largely determine the temporal and spatial scales of in-cloud vertical motions. This suggests that the system of in-cloud vertical motions is primarily cloud-generated and resilient to the thermodynamic coupling nature between the surface and cloud (e.g., Morrison et al., 2012). However, we do find that the magnitude of in-cloud $w$ variance does increase for coupled cases compared to decoupled cases, and there is a distinct relationship between decreased scaled LWP and weaker $w$ variability within decoupled clouds. Further additional turbulent mixing through wind speed shear has been observed during the coupled cases, which may promote additional turbulence and $w$ variability in these cases.

Magnitudes of $w$ variance are reduced near cloud top relative to cloud mid- and base levels, but we have shown a coherency in vertical motion across the cloud layer. Furthermore, the correlation coefficients on cloud-generated timescales $(<20 \mathrm{~min})$ tend to be larger between adjacent levels (mid-top and mid-base) compared to the correlation between base and top levels. Recent studies have characterized the frequent feature of cloud top penetrating above the inversion base for low-level Arctic clouds (Sedlar and Tjernström, 2009; Sedlar et al., 2012), consistent with statistics of ther- modynamic profiles within the cloud layer in this study. Reduced $w$ variance together with a general shift in $w$ skewness near cloud top suggest that the upper $20-30 \%$ (75-150 m) of these AMPS exhibit a different dynamical structure than is observed in the lower $70 \%$ of the cloud; this vertical structure is also different than is found for stratocumulus at more southerly latitudes, where effective cloud-top radiative cooling initiates the buoyant overturning and causes $w$ variance to be largest near cloud top (Lothon et al., 2005; Hogan et al., 2009). Over the Arctic, the variability in vertical motions near cloud top appears instead to be influenced by a saturated temperature inversion layer (Solomon et al., 2011; Devasthale et al., 2011; Sedlar et al., 2012; Nygård et al., 2014), leading to droplet condensation and sustained cloudtop penetration within the inversion (Solomon et al., 2011), while the largest source of turbulence production is further within the cloud layer, where Sedlar et al. (2012) speculate the largest cloud LWCs (coldest portion of the cloud layer) are found.

\section{Conclusions}

Detailed cloud vertical motion characteristics in low-level Arctic mixed-phase stratocumulus (AMPS) derived from surface-based remote sensing instruments from ASCOS were analyzed in this study. Additionally, the relationship of vertical motion characteristics to some bulk cloud properties and thermodynamic conditions has been examined. The main conclusions from this study include the following:

- Sub-cloud thermodynamic stability indicates a common decoupling state between the surface and cloud layer, often with cloud-driven mixing penetrating below cloud base but limited in connection with surfacebased turbulent motions by a sub-cloud stable layer. Decoupled AMPS have recently been observed to be most common over sea ice (Sedlar et al., 2012; Shupe et al., 2013; Sotiropoulou et al., 2014) even though near-neutral stability is often observed in the lowest few hundred meters above the surface (Tjernström et al., 2004; 2012). We identify changing mesoscale forcing and horizontal thermodynamic advection as important mechanisms controlling the decoupling between cloud and surface generated turbulence.

- Vertical velocity skewness and variance profiles indicate fundamental differences relative to the profiles observed for lower-latitude stratocumulus. Velocity skewness was often positive (stronger, narrower updrafts) in the upper third $(75-150 \mathrm{~m})$ of the cloud layer, while negative (stronger, narrower downdrafts) from within the cloud down to cloud base. Negative skewness was larger when only a single low AMPS layer was present, indicating the increased potential for 
cloud-top longwave cooling and enhanced buoyancydriven turbulence. The layer of positive $w$ skewness near cloud top tends to correspond with the region where cloud top penetrates through the stable temperature inversion (e.g., Sedlar and Tjernström, 2009; Sedlar et al., 2012).

- Time-varying spectral analysis of $w$ has indicated distinct vertical coherency in vertical motions across adjacent levels of the cloud and across the full depth of the cloud layer. The correlation between variance at adjacent cloud levels is weakest and most variable at timescales quicker than approximately $4 \mathrm{~min}$; beyond $4 \mathrm{~min}$, median correlations increase and variability generally decreases. However, power spectra indicate a clear weakening of absolute $w$ variance with increasing height in cloud. Rather than vertical velocity variance production occurring near cloud top, as is observed in lower-latitude stratocumulus (e.g., Paluch and Lenschow, 1991; Lothan et al., 2005; Hogan et al., 2009), we find $w$ variance to be largest at and below a depth of approximately $75-150 \mathrm{~m}$ from cloud top in response to cloud-top penetration within the temperature inversion.

- For cloud-surface coupled conditions, the peak in absolute $w$ variance occurred at 2-6 min timescales that are characteristic of cloud-generated turbulence; these timescales increased to 5-9 $\mathrm{min}$ and were weaker in decoupled cases. Only small increases in peak spectral horizontal wavelengths were observed between coupled and decoupled cases, due in part to slower horizontal winds. Thus, the characteristic temporal and spatial scales of cloud-generated vertical motions were not significantly different between the coupling states.

- Cloud-layer scaled LWPs were shown to positively correspond with the magnitude of $w$ variance, suggesting that cloud water formation is enhanced when coupling is ongoing, and/or vice versa. Nevertheless, there is nearly always cloud-generated mixing occurring below cloud base to some depth within the subcloud layer. Wind speed shear near the bottom of the mixed layer may enhance the thermodynamic coupling of the cloud to surface via mechanical mixing.

- The thermodynamic coupling state between surface and cloud layer appears more dependent on local meteorological forcing and the presence of cloud above shielding the lower cloud rather than being a function solely on the cloud-generated vertical motion variability, consistent with the conclusions of Shupe et al. (2013).

Although only a weeklong period of AMPS has been examined, the characteristics observed reveal insights into a system that is conditioned for, and supports, the lifecycle of these clouds. Results discussed in this study provide a previously undocumented glimpse into the dominant vertical velocity characteristics evident in high-latitude, low-level AMPS over sea ice. Results presented here can serve as observational constraints for cloud-resolving model studies. Such studies may lead towards further insights into the key mechanisms controlling vertical motions within these clouds.

Acknowledgements. We are grateful to the three reviewers for comments and suggestions which improved the scientific findings of this study. This work is part of the ASCOS (Arctic Summer Cloud Ocean Study) and was funded by the Swedish Science Research Council (VR) and the DAMOCLES European Union 6th Framework Programme Integrated Research Project. ASCOS was made possible by funding from the Knut and Alice Wallenberg Foundation. J. Sedlar was also funded by the Bert Bolin Centre for Climate Research at Stockholm University. We are grateful to the co-chief scientists C. Leck and M. Tjernström, as well as to the Oden's captain M. Peterson and crew.

Edited by: M. Tjernström

\section{References}

Birch, C. E., Brooks, I. M., Tjernström, M., Shupe, M. D., Mauritsen, T., Sedlar, J., Lock, A. P., Earnshaw, P., Persson, P. O. G., Milton, S. F., and Leck, C.: Modelling atmospheric structure, cloud and their response to $\mathrm{CCN}$ in the central Arctic: ASCOS case studies, Atmos. Chem. Phys., 12, 3419-3435, doi:10.5194/acp-12-3419-2012, 2012.

Curry, J. A.: Interacations among Turbulence, Radiation and Microphysics in Arctic Stratus Clouds, J. Atmos. Sci., 43, 90-106, 1986.

Curry, J. A., Rossow, W. B., Randall, D., and Schramm, J. L.: Overview of Arctic Cloud and Radiation Characteristics, J. Climate, 9, 1731-1764, 1996.

de Boer, G., Eloranta, E. W., and Shupe, M. D.: Arctic Mixed-phase Stratiform Cloud Properties from Multiple Years of SurfaceBased Measurements at Two High-Latitude Locations, J. Atmos. Sci., 66, 2874-2887, doi:10.1175/2009JAS3029.1, 2009.

de Boer, G., Morrison, H., Shupe, M. D., and Hildner, R.: Evidence of liquid dependent ice nucleation in high-latitude stratiform clouds from surface remote sensors, Geophys. Res. Lett., 38, L01803, doi:10.1029/2010GL046016, 2011.

Devasthale, A., Sedlar, J., and Tjernström, M.: Characteristics of water-vapour inversions observed over the Arctic by Atmospheric Infrared Sounder (AIRS) and radiosondes, Atmos. Chem. Phys., 11, 9813-9823, doi:10.5194/acp-11-9813-2011, 2011.

Harrington, J. Y., Reisin, T., Cotton, W. R., and Kreidenweis, S. M.: Cloud resolving simulations of Arctic stratus Part II: Transitionseason clouds, Atmos. Res., 51, 45-75, 1999.

Herman, G. and Goody, R.: Formation and Persistence of Summertime Arctic Stratus Clouds, J. Atmos. Sci., 33, 1537-1553, 1976.

Hildebrand, P. H. and Sekhon, R. S.: Objective Determination of the Noise Level in Doppler Spectra, J. Appl. Meteorol., 13, 808-811, 1974. 
Hogan, R. J., Grant, A. L. M., Illingworth, A. J., Pearson, G. N., and O'Connor, E. J.: Vertical velocity variance and skewness in clear and cloud-topped boundary layers as revealed by Doppler lidar, Q. J. Roy. Meteor. Soc., 135, 635-643, doi:10.1002/qj.413, 2009.

Intrieri, J. M., Fairall, C. W., Shupe, M. D., Persson, P. O. G., Andreas, E. L., Guest, P. S., and Moritz, R. E.: An annual cycle of Arctic surface cloud forcing at SHEBA, J. Geophys. Res., 107, 8039, doi:10.1029/2000JC000439, 2002a.

Intrieri, J. M., Shupe, M. D., Uttal, T., and McCarty, B. J.: An annual cycle of Arctic cloud characteristics observed by radar and lidar at SHEBA, J. Geophys. Res., 107, 8030, doi:10.1029/2000JC000423, 2002b.

Klein, S. A. and Hartmann, D. L.: The Seasonal Cycle of Low Stratiform Clouds, J. Climate, 6, 1587-1606, 1993.

Kupiszewski, P., Leck, C., Tjernström, M., Sjogren, S., Sedlar, J., Graus, M., Müller, M., Brooks, B., Swietlicki, E., Norris, S., and Hansel, A.: Vertical profiling of aerosol particles and trace gases over the central Arctic Ocean during summer, Atmos. Chem. Phys., 13, 12405-12431, doi:10.5194/acp-13-12405-2013, 2013.

Lothon, M., Lenschow, D. H., Leon, D., and Vali, G.: Turbulence measurements in marine stratocumulus with airborne Doppler radar, Q. J. Roy. Meteor. Soc., 131, 2063-2080, doi:10.1256/qj.04.131, 2005.

Mauritsen, T., Sedlar, J., Tjernström, M., Leck, C., Martin, M., Shupe, M., Sjogren, S., Sierau, B., Persson, P. O. G., Brooks, I. M., and Swietlicki, E.: An Arctic CCN-limited cloud-aerosol regime, Atmos. Chem. Phys., 11, 165-173, doi:10.5194/acp-11165-2011, 2011.

McFarquhar, G. M., Ghan, S., Verlinde, J., Korolev, A., Strapp, J. W., Schmid, B., Tomlinson, J. M., Wolde, M. Brooks, S. D., Cziczo, D., Dubey, M. K., Fan, J., Flynn, C., Gultepe, I., Hubbe, J., Gilles, M. K., Laskin, A., Lawson, P., Leaitch, W. R., Liu, P., Liu, X., Lubin, D., Mazzoleni, C. Macdonald, A.-M., Moffet, R. C., Morrison, H., Ovchinnikov, M., Shupe, M. D., Turner, D. D., Xie, S. Zelenyuk, A., Bae, K., Freer, M. and Glen, A.: Indirect and Semi-direct Aerosol Campaign. The Impact of Arctic Aerosols on Clouds, B. Am. Meteorol. Soc., 92, 183-201, doi:10.1175/2010BAMS2935.1, 2011.

Moeng, C.-H.: Large-eddy simulation of a stratus-topped boundary layer. Part I: Structure and budgets, J. Atmos. Sci., 43, 28862900, 1986.

Moran, K. P., Martner, B. E., Post, M. J., Kropfli, R. A., Welsh, D. C., and Widener, K. B.: An Unattended Cloud-Profiling Radar for Use in Climate Research, B. Am. Meteorol. Soc., 79, 443455, 1998.

Morrison, H., de Boer, G., Feingold, G., Harrington, J., Shupe, M. D., and Sulia, K.: Resilience of persistent Arctic mixed-phase clouds, Nat. Geosci., 5, 11-17, doi:10.1038/ngeo1332, 2012.

Nicholls, S. and Leighton, J.: An observational study of the structure of stratiform cloud sheets: Part I. Structure, Q. J. Roy. Meteor. Soc., 112, 431-460, 1986.

Nicholls, S. and LeMone, M. A.: The fair weather boundary layer in GATE: Relationship of subcloud fluxes and structure to the distribution and enhancement of cumulus clouds, J. Atmos. Sci., 37, 2051-2067, 1980.

Nygård, T., Valkonen, T., and Vihma, T.: Characteristics of Arctic low-tropospheric humidity inversions based on radio soundings,
Atmos. Chem. Phys., 14, 1959-1971, doi:10.5194/acp-14-19592014, 2014.

Paluch, I. R. and Lenschow, D. H.: Stratiform Cloud Formation in the Marine Boundary Layer, J. Atmos. Sci., 48, 2141-2158, 1991.

Paluch, I. R., Lenschow, D. H., and Wang, Q.: Arctic boundary layer in the fall season over open and frozen sea, J. Geophys. Res., 102, 25955-25971, 1997.

Pinto, J. O.: Autumnal Mixed-Phase Cloudy Boundary Layers in the Arctic, J. Atmos. Sci., 55, 2016-2038, 1998.

Pruppacher, H. R. and Klett, J. D.: Microphysics of Clouds and Precipitation, 2nd Edn., Kluwer Academic Publishers, 954 pp., 1996.

Rogers, D. P., Businger, J. A., and Charnock, H.: A numerical investigation of the JASIN atmospheric boundary layer, Bound.-Lay. Meteorol., 32, 373-399, 1985.

Sedlar, J. and Tjernström, M.: Stratiform Cloud-Inversion Characterization During the Arctic Melt Season, Bound.-Lay. Meteorol., 132, 455-474, doi:10.1007/s10546-009-9407-1, 2009.

Sedlar, J., Tjernström, M., Mauritsen, T., Shupe, M. D., Brooks, I. M., Persson, P. O. G., Birch, C. E., Leck, C., Sirevaag, A., and Nicolaus, M.: A transitioning Arctic surface energy budget: the impacts of solar zenith angle, surface albedo and cloud radiative forcing, Clim. Dynam., 37, 1643-1660, doi:10.1007/s00382010-0937-5, 2011.

Sedlar, J., Shupe, M. D., and Tjernström, M.: On the Relationship between Thermodynamic Structure and Cloud Top, and Its Climate Significance in the Arctic, J. Climate, 25, 2374-2393, doi:10.1175/JCLI-D-11-00186.1, 2012.

Shupe, M. D.: Clouds at Arctic Atmospheric Observatories. Part II: Thermodynamic Phase Characteristics, J. Appl. Meteorol. Clim., 50, 645-661, doi:10.1175/2010JAMC2468.1, 2011.

Shupe, M. D. and Intrieri, J. M.: Cloud Radiative Forcing of the Arctic Surface: The Influence of Cloud Properties, Surface Albedo, and Solar Zenith Angle, J. Climate, 17, 616-628, 2004.

Shupe, M. D., Matrosov, S. Y., and Uttal, T.: Arctic MixedPhase Cloud Properties Derived from Surface-Based Sensors at SHEBA, J. Atmos. Sci., 63, 697-711, 2006.

Shupe, M. D., Kollias, P., Persson, P. O. G., and McFarquhar, G. M.: Vertical Motions in Arctic Mixed-Phase Stratiform Clouds, J. Atmos. Sci., 65, 1304-1322, doi:10.1175/2007JAS2479.1, 2008a.

Shupe, M. D., Kollias, P., Poellot, M., and Eloranta, E.: On Deriving Vertical Air Motions from Cloud Radar Doppler Spectra, J. Atmos. Ocean. Tech., 25, 547-557, doi:10.1175/2007JTECHA1007.1, 2008b.

Shupe, M. D., Walden, V. P., Eloranta, E., Uttal, T., Campbell, J. R., Starkweather, S. M., and Shiobara, M.: Clouds at Arctic Atmospheric Observatories. Part I: Occurrence and Macrophysical Properties, J. Appl. Meteorol. Clim., 50, 626-644, doi:10.1175/2010JAMC2467.1, 2011.

Shupe, M. D., Brooks, I. M., and Canut, G.: Evaluation of turbulent dissipation rate retrievals from Doppler Cloud Radar, Atmos. Meas. Tech., 5, 1375-1385, doi:10.5194/amt-5-1375-2012, 2012.

Shupe, M. D., Persson, P. O. G., Brooks, I. M., Tjernström, M., Sedlar, J., Mauritsen, T., Sjogren, S., and Leck, C.: Cloud and boundary layer interactions over the Arctic sea ice in late summer, Atmos. Chem. Phys., 13, 9379-9399, doi:10.5194/acp-139379-2013, 2013. 
Solomon, A., Shupe, M. D., Persson, P. O. G., and Morrison, H.: Moisture and dynamical interactions maintaining decoupled Arctic mixed-phase stratocumulus in the presence of a humidity inversion, Atmos. Chem. Phys., 11, 10127-10148, doi:10.5194/acp-11-10127-2011, 2011.

Sotiropoulou, G., Sedlar, J., Tjernström, M., Shupe, M. D., Brooks, I. M., and Persson, P. O. G.: The thermodynamic structure of summer Arctic stratocumulus and the dynamic coupling to the surface, Atmos. Chem. Phys. Discuss., 14, 3815-3874, doi:10.5194/acpd-14-3815-2014, 2014.

Stull, R. B.: An Introduction to Boundary Layer Meteorology, Kluwer Academic Publishers, 666 pp., 1988.

Tjernström, M. and Mauritsen, T.: Mesoscale Variability in the Summer Arctic Boundary Layer, Bound.-Lay. Meteorol., 130, 383-406, doi:10.1007/s10546-009-9354-x, 2009.

Tjernström, M., Birch, C. E., Brooks, I. M., Shupe, M. D., Persson, P. O. G., Sedlar, J., Mauritsen, T., Leck, C., Paatero, J., Szczodrak, M., and Wheeler, C. R.: Meteorological conditions in the central Arctic summer during the Arctic Summer Cloud Ocean Study (ASCOS), Atmos. Chem. Phys., 12, 6863-6889, doi:10.5194/acp-12-6863-2012, 2012.

Tjernström, M., Leck, C., Birch, C. E., Bottenheim, J. W., Brooks, B. J., Brooks, I. M., Bäcklin, L., Chang, R. Y.-W., de Leeuw, G., Di Liberto, L., de la Rosa, S., Granath, E., Graus, M., Hansel, A., Heintzenberg, J., Held, A., Hind, A., Johnston, P., Knulst, J., Martin, M., Matrai, P. A., Mauritsen, T., Müller, M., Norris, S. J., Orellana, M. V., Orsini, D. A., Paatero, J., Persson, P. O. G., Gao, Q., Rauschenberg, C., Ristovski, Z., Sedlar, J., Shupe, M. D., Sierau, B., Sirevaag, A., Sjogren, S., Stetzer, O., Swietlicki, E., Szczodrak, M., Vaattovaara, P., Wahlberg, N., Westberg, M., and Wheeler, C. R.: The Arctic Summer Cloud Ocean Study (ASCOS): overview and experimental design, Atmos. Chem. Phys., 14, 2823-2869, doi:10.5194/acp-14-2823-2014, 2014.
Torrence, C. and Compo, G. P.: A Practical Guide to Wavelet Analysis, B. Am. Meteorol. Soc., 79, 61-78, 1998.

Walsh, J. E. and Chapman, W. L.: Arctic Cloud-RadiationTemperature Associations in Observational Data and Atmospheric Reanalyses, J. Climate, 11, 3030-3045, 1998.

Westwater, E. R., Han, Y., Irisov, V. G., Leuskiy, V., Kadygrov, E. N., and Viazankin, S. A.: Remote Sensing of Boundary Layer Temperature Profiles by a Scanning 5-mm Microwave Radiometer and RASS: Comparison Experiments, J. Atmos. Ocean. Tech., 16, 805-818, 1999.

Westwater, E. R., Han, Y., Shupe, M. D., and Matrosov, S. Y.: Analysis of integrated cloud liquid and precipitable water vapor retrievals from microwave radiometers during the Surface Heat Budget of the Arctic Ocean project, J. Geophys. Res., 106, 32019-32030, 2001. 